M. Nasir Khan · Mohammad Mobin

Firoz Mohammad - Francisco J. Corpas

Editors

Nitric Oxide Action

in Abiotic Stress

Responses in Plants 


\section{Editors}

M. Nasir Khan

Faculty of Science, Department of Biology

University of Tabuk

Tabuk

Saudi Arabia

Mohammad Mobin

Faculty of Science, Department of Biology

University of Tabuk

Tabuk

Saudi Arabia
Firoz Mohanmad

Department of Botany

Aligarh Muslim University

Aligarh

India

Francisco J. Corpas

Departamento de Bioquímica Biol. Cellular y Molecular de Plantas

Estación Experimental del Zaidín

Granada

Spain

ISBN 978-3-319-17803-5

DOI 10.1007/978-3-319-17804-2

ISBN 978-3-319-17804-2 (eBook)

Library of Congress Control Number: 2015936465

Springer Cham Heideiberg New York Dordrecht London

() Springer International Publishing Switzerland 2015

This work is subject to copyright. All rights are reserved by the Publisher, whether the whole or part of the material is concerned, specifically the rights of transiation, reprinting, reuse of illustrations, recitation, broadcasting, reproduction on microfilms or in any other physical way, and transmission or information storage and retrieval, electronic adaptation, computer software, or by similar or dissimilar methodology now known or hereafter developed.

The use of general descriptive names, registered names, trademarks, service marks, etc. in this publication does not imply, even in the absence of a specific statement, that such names are exempt from the relevant protective laws and regulations and therefore free for general use.

The publisher, the authors and the editors are safe to assume that the advice and information in this book are believed to be true and accurate at the date of publication. Neither the publisher nor the authors or the editors give a warranty, express or implied, with respect to the material contained herein or for any errors or omissions that may have been made.

Printed on acid-free paper 


\section{Foreword}

Plants are essential to life on Earth, and they have been harnessed by humans for food, fuel, and many other purposes. The need to increase crop production is becoming more urgent due to increasing population and diversion of crops to biofuels production. Furthermore, this increase in production needs to be done sustainably, with reduced inputs, and in the face of global environmental change. It is also notable that at least one-third of the world's food production is grown under irrigation - much of this irrigation is unsustainable, using water supplies that are both overexploited and under threat from changing weather patterns resulting from global climate change. To meet the consensus targets for increased food production by 2050 , significant increases in historical annual increases in production are required, which requires substantial innovations in agricultural production. Many of these innovations must ultimately come from, among other sources, plant science research. One important and relevant area of this plant science research is covered in-depth in this book.

The gap between potential yield and actual yield is primarily due to the effects of abiotic stresses on crop production. It is therefore an imperative to improve our ability to maintain crop production in environments with suboptimal conditions such as low water or nutrient supplies, or high salinity. One of the key components of plant responses to these abiotic stresses is nitric oxide (NO). Understanding the role of NO in the control of plant reactions provides fundamental information to underpin the much-needed innovations to come in global food production.

As such, the book edited by Drs. Khan, Mobin, Mohammad, and Corpas provides a useful and timely compilation of up-to-date overviews of advances in the important area of plant sciences, "Nitric Oxide Action in Abiotic Stress Responses in Plants." In this volume, a range of papers have been brought together which address the multifarious roles of NO in plant function and the responses of plants to many abiotic stresses. The breadth of areas covered in this volume highlights well the importance of this simple molecule and thus the utility of this compilation. The highly international set of contributors, including many from developing countries, is also both valuable and encouraging. 
Valentovicová K, Halusková L, Huttová J et al (2010) Effect of cadmium on diaphorase activity and nitric oxide production in barley root tips. J Plant Physiol 167:10-14

Vandelle E, Delledonne M (2011) Peroxynitrite formation and function in plants. Plant Scl 181:534-539

Wang L, Yang L, Yang $\mathrm{F}$ et al (2010a) Involvements of $\mathrm{H}_{2} \mathrm{O}_{2}$ and metallothionein in NO-mediated tomato tolerance to copper toxicity. J Plant Physiol 167:1298-1306

Wang SH, Zhang H, Jiang SJ et al (2010b) Effects of the nitric oxide donor sodium nitroprusside. on antioxidant enzymes in wheat seedling roots under nickel stress. Russian J Plant Physiol 57:833-839

Wendehenne D, Lamotte O, Pugin A (2003) Plant iNOS: conquest of the Holy Grail. Trends Plant Sci 8:465-468

Wilkinson JQ, Crawford NM (1993) Identification and characterization of a chlorate resistant mutant of Arabidopsis with mutations in both NIA1 and NIA2 nitrate reductase structural genes. Mol Gen Genet 239:289-297

Xiong J, An L, Lu H, Zhu C (2009a) Exogenous nitric oxide enhances cadmium tolerance by increasing pectin and hemicellulose contents in root cell wall. Planta 230:755-765

Xiong J, Lu H, Lu K et al (2009b) Cadmium decreases crown root number by decreasing endog. enous nitric oxide, which is indispensable for crown root primordia initiation in rice seedlings. Planta 230:599-610

Xu YC, Zhao BL (2003) The main origin of endogenous NO in higher non-leguminous plants. Plant Physiol Biochem 41:833-838

Xu J, Wang W, Yin H et al (2010a) Exogenous nitric oxide improves antioxidative capacity and reduces auxin degradation in roots of Medicago truncatula seedlings under cadmium stress. Plant Soil 326:321-330

Xu J, Yin H, Li Y, Liu X (2010b) Nitric oxide is associated with long-term zinc tolerance in Solanum nigrum. Plant Physiol 154:1319-1334

Yang L-T, Qi Y-P, Chen L-S et al (2012) Nitric oxide protects sour pummelo (Citrus grandis) seedlings against aluminum-induced inhibition of growth and photosynthesis. Environ Exp Bot 82:1-13

Zhang LP, Mehta SK, Liu ZP, Yang ZM (2008) Copper-induced proline synthesis is associated with nitric oxide generation in Chlamydomonas reinhardtii. Plant Cell Physiol 49:411-419 


\title{
Chapter 13 \\ Role of Nitric Oxide in Salt Stress-induced Programmed Cell Death and Defense Mechanisms
}

\author{
Péter Poór, Gábor Laskay and Irma Tari
}

\begin{abstract}
During the last decade, it has been shown by several authors and in several plant species that nitric oxide (NO) accumulates in tissues exposed to high salinity. This gaseous-free radical and signaling compound can attenuate the ionic component of salt stress by enhancing $\mathrm{Na}^{+}$extrusion from the cells via $\mathrm{Na}^{+} / \mathrm{H}^{+}$ exchange through the activation of plasma membrane and vacuolar $\mathrm{H}^{+}$-ATPases and $\mathrm{H}^{+}$-pyrophosphatase. NO alleviates the osmotic stress caused by high salt concentrations by stimulating the biosynthesis of compatible osmolytes such as proline, glycine betaine, and soluble sugars, and it also protects the cells from the oxidative damage by enhancing non-enzymatic and enzymatic antioxidants. However, NO may promote programmed cell death (PCD) depending on the NO scavenging capacity of the cells and on the cellular redox status as well as on the flux and dose of local reactive nitrogen and oxygen forms generated in various cell compartments. Particular attention is paid to the role of NO and NO-induced protein modifications in the activation of specific steps of PCD during salt stress.
\end{abstract}

Keywords High salinity - Nitric oxide - Programmed cell death - Reactive oxygen species - Salt stress

\subsection{Introduction}

It is estimated that more than $6 \%$ of the total land area and about $30 \%$ of the world's irrigated area are salt affected and the increasing secondary salinization of soil and groundwater is one of the most important environmental factors that decrease the productivity of crop plants (Munns 2002; Lambers 2003).

P. Poór $(\mathrm{B}) \cdot \mathrm{G}$. Laskay · I. Tari

Department of Plant Biology, University of Szeged, Közép fasor 52,

Szeged H-6726, Hungary

s-mail: poorpeti@bio.u-szeged.hu 
High salinity imposes osmotic stress on plants by preventing water uptake of root tissues and causes a rapid reduction in stomatal closure, transpiration, photosynthesis, and eventually in shoot growth rate. The salt-specific ionic effects appear later and the excessive amount of $\mathrm{NaCl}$ in leaf tissues results in premature senescence of older leaves, decreases the biomass production, and finally it may induce programmed cell death (PCD) in root or leaf tissues of salt-sensitive species or genotypes (Munns and Tester 2008; Shabala 2009). Understanding the mechanisms that regulate salt tolerance and the salt-induced PCD at the molecular, cellular, tissue, or whole-plant levels is an important problem in plant biology and molecular biological technics speeded up the elucidation of the distinct and relevant responses in salt-tolerant and sensitive plants. Nitric oxide (NO) is a biologically active gaseous-free radical that transmits the environmental or hormonal signals during different biotic and abiotic stresses including salt stress (Corpas et al. 2011). Salt-induced NO generation in parallel with hydrogen peroxide $\left(\mathrm{H}_{2} \mathrm{O}_{2}\right)$ accumulation can act both independently and synergistically, and they are involved in several downstream signal transduction pathways determining cell fate (Siddiqui et al. 2011). In the past ten years, the role of NO in salt tolerance and salt toxicity has been studied using exogenously applied NO generators, NO scavengers, and mutant plants with higher or lower activities in NO production. These plants have generally but not exclusively mutations in the genes encoding the most important enzymes participating in NO biosynthesis or NO levels may be controlled by specific inhibitors.

In this review, we highlight the current state of the art of the physiological and molecular aspects of $\mathrm{NaCl}$-induced $\mathrm{NO}$ signaling in plants and discuss the roles of endogenous and exogenous $\mathrm{NO}$ in $\mathrm{NaCl}$ toxicity and salt tolerance mechanisms.

\section{2 $\mathrm{NaCl}$ Tolerance in Plants}

Plant responses to salt stress can be divided into two phases: A rapid, osmotic phase that inhibits the growth of young leaves, and a slower, ionic phase that elicits ion-specific effects and accelerates senescence of mature leaves (Munns and Tester 2008). It can be concluded, however, that the effects of salt stress depend not only on the concentration of $\mathrm{NaCl}$ but also on the duration of the stress and on the age and sensitivity of the plants. Salt stress-induced osmotic, ionic, and oxidative stresses cause strong toxicity and finally induce PCD in sensitive species (Zhu 2002) while salt-tolerant plants, especially the halophytes, might be growing at their optimum rate at the same salt concentration.

Munns and Tester (2008) defined three distinct types of plant adaptation to highsalinity: osmotic stress tolerance, the exclusion of $\mathrm{Na}^{+}$or $\mathrm{Cl}^{-}$ions from the cells, and tissue tolerance that is the tolerance of $\mathrm{Na}^{+}$after vacuolar sequestration inside the cells.

Salt stress reduces water uptake by the roots leading to a reduction in relative 
in growth inhibition, stomatal closure, and a decrease in photosynthesis (Munns and Tester 2008). These short-term changes are solely due to osmotic stress evoked by high salinity. The balance of osmotic potential between the soil solution and cell compartments can be achieved by the accumulation of compatible solutes such as proline (Pro), glycine betaine, mannitol, or sugars. They can also act as osmoprotectants because their high concentration in the cytosol and organelles is beneficial for the maintenance of the tertiary structure of proteins (Rhodes et al. 2004). Halophytes or salt-tolerant glycophytes with high tissue tolerance can use $\mathrm{Na}^{+}$for osmotic adjustment after its sequestration into the vacuole (Munns and Tester 2008).

Plants have multiple $\mathrm{Na}^{+}$transport systems to circumvent salt toxicity. The maintenance of the optimal $\mathrm{K}^{+} / \mathrm{Na}^{+}$ratio, the high $\mathrm{K}^{+}$, and low $\mathrm{Na}^{+}$concentrations in the cytoplasm are of primary importance to protect cellular functions (Zhu 2003). In barley high-affinity $\mathrm{Na}^{+}$uptake trough, a uniporter was inhibited by external $\mathrm{K}^{+}$in long-term experiments (Haro et al. 2005), suggesting that the uptake of sodium depends on the $\mathrm{K}^{+} / \mathrm{Na}^{+}$discrimination of the transporter system. The removal of the excess $\mathrm{Na}^{+}$from the cytoplasm occurs by secondary active transport through $\mathrm{Na}^{+} / \mathrm{H}^{+}$antiporters which can be localized to the plasma membrane (PM) and tonoplast, the former is known as SOS1 in Arabidopsis and the latter is the member of NHX vacuolar exchanger family (Blumwald 2000, Hasegawa et al. 2000). The importance of these antiporters to improve salt tolerance was confirmed by the overexpression of vacuolar $\mathrm{Na}^{+} / \mathrm{H}^{+}$(AtNHX1) or PM (SOS1) antiporter genes in Arabidopsis (Zhu 2002; Pardo et al. 2006). SOS1 is preferentially expressed in the xylem parenchyma cells, suggesting a role of this antiporter in loading $\mathrm{Na}^{+}$into the xylem (Pardo et al. 2006). $\mathrm{Na}^{+} / \mathrm{H}^{+}$antiporter activity is driven by the electrochemical proton gradient generated by $\mathrm{H}^{+}$pumps, such as PM and vacuolar $\mathrm{H}^{+}$-ATPases and $\mathrm{H}^{+}$-pyrophosphatase $\left(\mathrm{H}^{+}\right.$-PPase $)$ (Hasegawa et al. 2000). Zhang et al. (2006) found that the salt stress-induced increase in vacuolar $\mathrm{H}^{+}$-ATPase and $\mathrm{H}^{+}$-PPase activities resulted in an increased $\mathrm{H}^{+}$translocation, $\mathrm{Na}^{+} / \mathrm{H}^{+}$exchange, and enhanced salt tolerance. Recent research has demonstrated that the members of HKT transporter family play an essential role in $\mathrm{Na}^{+}$exclusion from the leaves under salt stress. Arabidopsis HKT1;1 was found to localize to the plasma membrane of xylem parenchyma cells and this transporter mediates the removal of $\mathrm{Na}^{+}$from the xylem sap via $\mathrm{Na}^{+}$uptake into xylem parenchyma cell (Horie et al. 2009). Comparing the salt stress-induced gene expression of the salt-sensitive Arabidopsis thaliana with its salt-tolerant relative Thellungiella salsuginea (previously Thellungiella halophyla), the salt-tolerant species showed stress-specific and stress intensity-dependent responses and a fundamental difference was found in the steady-state amount of SOS1 and other salt stress-related mRNAs and in the level of their induction during salt stress (Dassanayake et al. 2011).

Various sub-cellular organelles or cell compartments such as chloroplasts, mitochondria, peroxisomes, and the apoplast are common sites of reactive oxygen species (ROS) production under high salinity (Ashraf 2009). The survival of plants under 
ROS by various antioxidant systems (Foyer and Noctor 2005; Miller et al. 2010). These enzymes act as ROS scavengers to alleviate the salt-induced oxidative damage in distinct cell compartments. Superoxide dismutase (SOD) catalyzes the dismutation of superoxide radical into molecular oxygen and hydrogen peroxide $\left(\mathrm{H}_{2} \mathrm{O}_{2}\right) . \mathrm{H}_{2} \mathrm{O}_{2}$ can be scavenged by peroxidases (POX), especially by ascorbate- or glutathione peroxidase (APX or GPX) and by catalase (CAT). Glutathione reductase (GR) recycles oxidized glutathione (GSSG) to glutathione (GSH) using NADPH to re-establish the reduced GSH pool (Miller et al. 2010). These' enzymes, in accordance with non-enzymatic antioxidants such as ascorbate (ASA), GSH, tocopherol, and flavonoids (Foyer and Noctor 2003), maintain appropriate $\mathrm{H}_{2} \mathrm{O}_{2}$ levels required for signal transduction processes under salt stress. The association of high levels of non-enzymatic antioxidants and the high activity of ascorbate-glutathione cycle with salt tolerance can be observed in several species (Ashraf 2009), but the activities of antioxidant enzymes were not a reliable criterion for salt tolerance in some species from the Brassicaceae family (Siegal et al. 1982).

Similarly, the accumulation of polyamines, putrescine (Put), spermidine (Spd), and spermine (Spm) is associated with salt stress (Gill and Tuteja 2010) because they have a positive effect on the maintenance of ion balance, membrane stabilization, and ROS scavenging in plants and inhibit both lipid peroxidation and stress-induced oxidative reactions (Ashraf and Harris 2004; Groppa and Benavides 2008). Alternatively, polyamines can act as prooxidants because their catabolism by the activities of diamine oxidase (DAO) and polyamine oxidases (PAO) produces $\mathrm{H}_{2} \mathrm{O}_{2}$, which can induce PCD (Cona et al. 2006; Yoda et al. 2006; Moschou et al. 2008; Wimalasekera et al. 2011).

Photosynthesis is among the primary processes affected by salinity. The osmotic component of salt stress restricts $\mathrm{CO}_{2}$ availability by limitation of its diffusion through stomata and mesophyll. Ionic effects can seriously inhibit the photosynthetic metabolism; excessive $\mathrm{Na}^{+}$or $\mathrm{Cl}^{-}$accumulation in chloroplasts leads to the degradation of chlorophyll, damage to light-harvesting complexes, suppression of PS II activity (Mehta et al. 2010), and reduced efficiency of ribulose-1,5-bisphosphate carboxylase (Rubisco) (Abdel-kader et al. 2007; Chaves et al. 2009). Genes or proteins associated with photosynthesis are not among the most altered genes in plants exposed to salt stress. It was found that larger alterations can be observed at transcriptomic level (5-10\%) than at protein level $(<1 \%)$ (Chaves et al. 2009). Several genes encoding proteins of the photosynthetic apparatus (subunits of ATP synthase, proteins from PS II and PS I) or enzymes of the Calvin cycle and photorespiration such as fructose-bisphosphatase, aldolase, phosphoribulokinase, glycine hydroxymethyltrasferase, or transketolase were downregulated by salt stress; however, the members of multigene families may be differently affected (Kilian et al. 2007).

The biomass production of plants is largely determined by the balance between photosynthesis and respiration. The respiration of tissues exposed to salt stress may increase or decrease or there are no consistent changes in respiratory rate in about one-third of the studies. Depending on salt tolerance strategy, a higher res- 
determines the carbon allocation from shoot to roots and thus the growth capacity of plant parts and it fuels the ATP requirement for the ion exclusion mechanisms in root tissues (Jakoby et al. 2011).

Respiratory rate of isolated plant mitochondria may be reduced by high salt concentrations. Mitochondrial electron transport produces ATP by utilizing the $\mathrm{H}^{+}$ electrochemical gradient generated by Complex I, Complex III, and Complex IV localized in the inner mitochondrial membrane. The activity of electron transport chain complexes, the NADH dehydrogenases (Complex I), and succinate dehydrogenase (Complex II) is inhibited at toxic $\mathrm{Na}^{+}$concentrations owing to protein denaturation and complex disassembly (Flowers 1974; Hamilton and Heckathorn 2001). Salt stress decreased the capacity of the cytochrome pathway, whereas the capacity of alternative oxidase (AOX) increased, which prevented the high reduction level of the ubiquinone pool. Since the major site of superoxide production along the respiratory chain is the ubiquinone pool, higher AOX activity plays a pivotal role in lowering mitochondrial ROS formation in plant cells (Jolivet et al. 1990; Smith et al. 2009). Mitochondria generate a large portion of cellular ROS, and a strong link exists between the mitochondrial antioxidant capacity and the salt tolerance of plants. ROS signals emanating from plant mitochondria determine the survival or death signals under salt stress (Dutilleul et al. 2003). Although nuclear-encoded mitochondrial proteins were over-represented anong salinity responsive proteins, there was no strict correlation between transcript level and protein abundance. In contrast, they showed an inverse relationship (reduced mRNS/increased protein abundance) in the cases of NADH dehydrogenase 39-kDa subunit and malate dehydrogenase while there was a decrease in both transcript and protein abundances of cytochrome $c$ oxidase subunit $6 \mathrm{~b}$ and fumarase in short-term experiments. Glutathione peroxidase and mitochondrial heat shock protein 70-2 were up-regulated at mRNS level while salt stress enhanced the protein abundance of Mn-SOD (Jiang et al. 2007; Taylor et al. 2009). This suggests that the protection of mitochondrial function under abiotic stress takes place by fast changes at transcriptional and protein levels.

\subsection{NaCl Toxicity and Salt-induced Cell Death in Plants}

PCD is an organized and controlled active cell suicide during the normal life cycle of plants and in response to changing environment. It can be triggered by the developmental program or by abiotic and biotic stressors and it is associated with specific biochemical and molecular hallmarks (van Doorn 2005; van Doorn and Woltering 2005; Gunawardena 2008; van Doorn 2011). Although the three main forms of animal PCD, the apoptosis, autophagy, and necrosis-like cell death, were compared with various types of plant $\mathrm{PCD}$, there is no clear correspondence between these main categories due to the presence of cell wall and the lack of phagocytes in plants. Cytoplasmic shrinkage, nuclear chromatin condensation, and finally the fragmentation of DNA, the hallmarks of animal apoptosis, are found in 
In animal cells, DNA fragmentation during apoptosis is catalyzed by a cysteinyl-âspartate specific proteinase, "caspase-"activated DNase which cleaves DNA into internucleosomal fragments. These cysteine proteases and caspases are central players of animal apoptosis. They exist as inactive proenzymes that are activated by proteolytic processing catalyzed by initiator caspases. They work in a cascade and cleave the inactive proenzyme of the down-stream effector caspases to form active heterodimers (Enari et al. 1998) which then degrade specific protein substrates. However, up to now, no homolog of animal caspases has been found in plants, but there are other enzymes, such as vacuolar processing enzyme (VPE) which exhibit caspase-like activities (Hatsugai et al. 2004). In plants, other celldeath-specific cysteine proteases and metacaspases show structural similarities to caspases, but they have proteolytic activity adjacent to arginine and lysine residues of the substrates (Woltering 2010). Metacaspases are involved in various types of cell death induced by abiotic stressors, e.g., oxidative stress (He et al. 2008). However, it was found that type I metacaspases suppress and type II metacaspases stimulate cell death program in plants (Woltering 2010).

Release of apoptogenic factors such as cytochrome $c$ (cyt c) from the intermembrane space of mithocondria is a common feature of animal and plant PCD which drives the assembly of the apoptosome, a caspase-activating complex in the cytoplasm of animal cells (Kroemer et al. 2007). The permeabilization of mitochondrial membrane and cyt $c$ release was associated with plant PCD as well, following death stimuli, such as heat shock, menadione, or ceramide treatments (reviewed by Reape and McCabe 2010).

In plants, the generation of excess amount of ROS was proposed as a key inducer of various types of PCD (De Pinto et al. 2012). Increased ROS, especially $\mathrm{H}_{2} \mathrm{O}_{2}$, may activate $\mathrm{PM}-\mathrm{Ca}^{2+}$ channels and increase $\left[\mathrm{Ca}^{2+}\right]_{\mathrm{cyt}}$ which is an inducer of the permeabilization of mitochondrial membranes. In animal cells, the integrity of the outer mitochondrial membrane is maintained through the balance of pro-apoptotic (Bax, Bak, Bad, Bid) and anti-apoptotic (Bcl-2 and $\mathrm{Bcl}-\mathrm{xL}$ ) proteins. These proteins can control the release of proteinaceous factors from the intermembrane space by controlling the formation of permeability transition pore (PTP) on the mitochondrial envelope through the interaction of voltage-dependent anion channel, the adenine nucleotide transporter, and cyclophilin D (Jones 2000). Although the pro-apoptotic Bax protein operates in PTP formation in animal systems and $\mathrm{Bcl}-2$ and $\mathrm{Bcl}-\mathrm{xL}$ antiapoptotic factors inhibit Bax action and can confer resistance to death, their plant homologs have not been identified yet. However, a cell death suppressor, Bax-inhibitor-1, has been reported in Arabidopsis plants that localizes to the endoplasmatic reticulum and exhibits a $\mathrm{pH}$-dependent $\mathrm{Ca}^{2+}$ channel-regulating activity (Ihara-Ohori et al. 2007; Kim et al. 2008).

The formation of PTP following stress-induced increase in $\left[\mathrm{Ca}^{2+}\right]_{\mathrm{cyl}}$ and ROS production leads to the loss of mitochondrial membrane potential $\left(\Delta \psi_{\mathrm{m}}\right)$ and to the release of cyt $c$ into the cytoplasm during PCD of plant cells, too. Although cyt $c$ does not appear to directly activate PCD in plants (Balk et al. 2003), its absence from the mitochondrial electron transport chain may lead to enhanced generation of ROS (Vianello et al 2007) However in rice an increased ROS nroduction 
preceded the cyt $c$ release from root mitochondria under salt stress. The analysis of the rice salt proteome by two-dimensional IEF/SDS-PAGE revealed that four mitochondrial proteins, glycoside hydrolase, mitochondrial heat shock protein 70 , $20 \mathrm{~S}$ proteasome subunit, and $\mathrm{Cu} / \mathrm{Zn}-\mathrm{SOD}$, were up-regulated during PCD induction (Chen et al. 2009).

Autophagic cell death, also known as type II cell death in animals, was characterized by a lack of chromatin condensation and by the appearance of autophagosomes, the double membrane-possessing structures. Autophagosomes contain hydrolytic enzymes and digest the engulfed cellular components, but their role as executioners of PCD has been debated in plants (Cacas and Diamond 2009). During micro-, macro-, and megaautophagy, the disappearance of organelles and cytoplasmic constituents occurs through the activity of lytic compartments (authophygosomes or vacuole) (van Doorn and Woltering 2005), which contributes to the recycling of cellular components, thus the outcome of authophagy is dependent on the plant fitness and may have a pro-life and/or pro-death function.

Salt stress-induced PCD is also accompanied by the retraction of the plasma membrane from the cell wall, condensation of the cytoplasm and the nucleus, DNA laddering, loss of membrane integrity, release of cytochrome $c$ from mitochondria, increase in caspase 3-like protease activity, and changes in the ion homeostasis and $\mathrm{K}^{+}$efflux (Fig. 13.1) (Wang et al. 2010a; Poór et al. 2013).
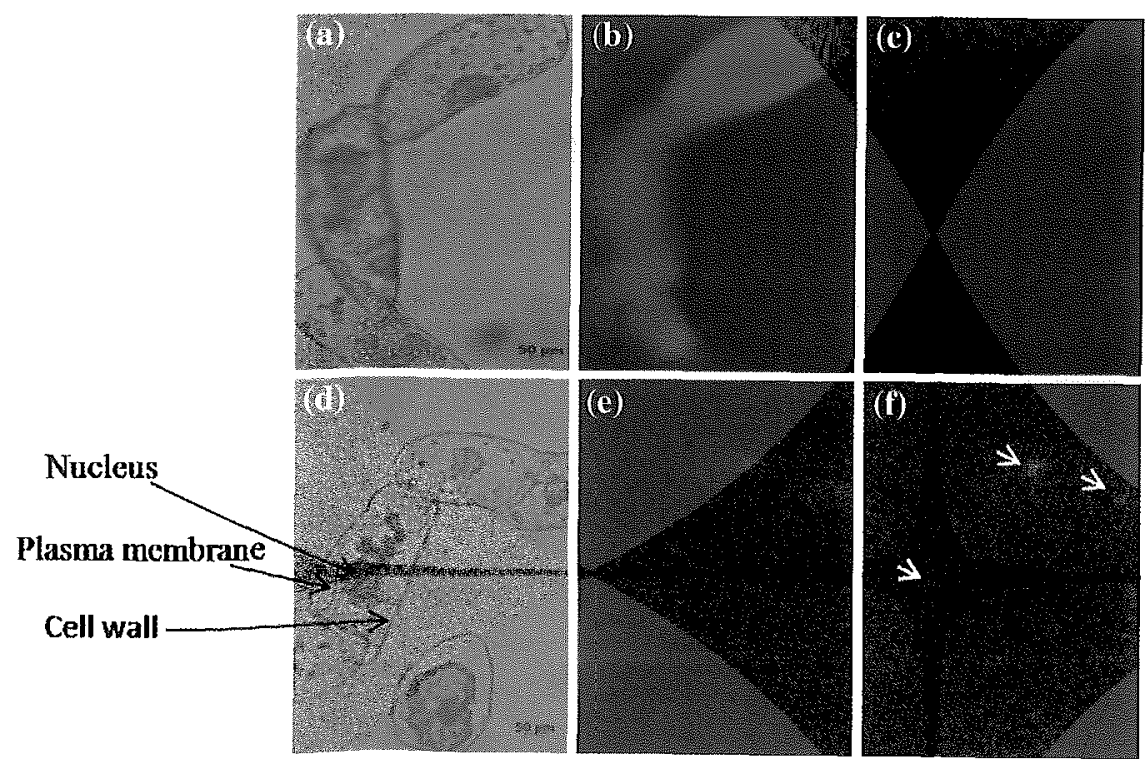

Fig. 13.1 Detection of DNA fragmentation by TUNEL staining in tomato cell suspension treated with $250 \mathrm{mM} \mathrm{NaCl}$ for $6 \mathrm{~h}$. Part A Control (a, b, c), $250 \mathrm{mM} \mathrm{NaCl}$ (d, e, f), bright field microscopy (a, d); Hoechst 33258 staining (b, e); TUNEL-positive nuclei $(f)$ (reproduced from 
$\mathrm{NaCl}$ has multiple ways to induce toxicity and cell death in plants. First, the $\mathrm{NaCl}$-induced osmotic stress reduces cell expansion in root tips and young leaves; however; the osmotic component of salt stress does not lead to the activation of the endonuclease involved in DNA degradation and it is not enough to induce PCD in plant cells. Affenzeller et al. (2009) reported that the exogenous treatment with sorbitol (an agent which induces only osmotic but not ionic stress) did not result in DNA laddering on agarose gel, which is one of the hallmarks of the apoptosis-like PCD.

Secondly, $\mathrm{NaCl}$ treatment induces ion disequilibrium in plant cells (Huh et al. 2002). Under saline conditions, $\mathrm{Na}^{+}$enters the cell cytoplasm through the nonselective cation channels (NSCC) causing membrane depolarization and resulting in $\mathrm{K}^{+}$leakage from the cell through depolarization-activated outward-rectifying $\mathrm{K}^{+}$(KOR) channels (Shabala 2009). The accumulation of toxic $\mathrm{Na}^{+}$can induce a loss of enzyme activities in the cells. The release of $\mathrm{K}^{+}$from the cytoplasm causes $\mathrm{K}^{+}$deficiency, which can activate cysteine proteases, the effectors of PCD (Shabala 2009; Demidchik et al. 2010). Potassium is required in many physiological processes of plants, including protein and nucleic acid synthesis. It can be concluded that the decrease in the cytoplasmic $\mathrm{K}^{+} / \mathrm{Na}^{+}$ratio is crucial for triggering PCD in living cells (Joseph and Jini 2010).

Finally, salt stress also causes strong oxidative stress-generating ROS such as singlet oxygen $\left({ }^{l} \mathrm{O}_{2}\right)$, superoxide radical $\left(\mathrm{O}_{2}^{-}\right)$, hydroxyl radical $(\mathrm{OH})$, and $\mathrm{H}_{2} \mathrm{O}_{2}$. which can react with lipids, proteins, and nucleic acids, inactivate enzymes, and enhance lipid peroxidation, membrane leakage, and DNA breakdown; thus, they can induce PCD. ROS are also involved in various signaling pathways such as those of plant hormones, e.g., abscisic acid, jasmonic acid, or ethylene during the plant stress responses (Van Breusegem and Dat 2006; De Pinto et al. 2012). Salt stress increases cytosolic $\left[\mathrm{Ca}^{2+}\right]$ and activates PM-bound NADPH oxidase, which generates superoxide in the apoplast. At the same time, ROS production causes $\mathrm{K}^{+}$efflux via ROS-activated NSCC channels, which also induces PCD (Shabala 2009). Other sources of ROS are the photosynthetic and respiratory electron transport chains or the peroxisomes (Foyer and Noctor 2003). In addition, the interaction of ROS and NO and the balance between antioxidants and hormone levels can adjust the induction of PCD or tolerance mechanisms in plants under high salinity.

\subsection{NO Production in Plants Exposed to $\mathrm{NaCl}$}

NO is a gaseous signaling molecule, which regulates a wide range of physiological and biochemical processes, and the growth and development of plants as well as their responses to biotic and abiotic stresses (Neill et al. 2003; Wendehenne et al. 2004; Delledone 2005; Corpas et al. 2011 ; Siddiqui et al. 2011).

In plant kingdom, NO can be generated non-enzymatically via reduction of nitrite to NO by the mitochondrial electron transport chain and by the reduction of apoplastic nitrite under acidic conditions. The enzymatic reduction of nitrite to NO is a function of nitrate reductase (NR) in nlant tissues (Yamasaki and Sakiham 2000) 
Arabidopsis NR is encoded by two nitrate reductase genes, NIA1 and NIA2, and nial/nia2 double mutant plants show low NO accumulation (Desikan et al. 2002; Bright et al. 2006). In this case, NO production can be reduced by specific NR inhibitors such as sodium azide $\left(\mathrm{NaN}_{3}\right)$ or tungstate (Bright et al. 2006; Sang et al. 2008).

Arginine (Arg)-dependent NO production by nitric oxide synthase (NOS)like activities suggests the presence of oxidative pathway of NO synthesis in plants (del Rio et al. 2004; Corpas et al. 2006). Plant NOS activity can be inhibited by animal NOS inhibitors that act as Arg analogs, such as NG-nitro-L-arginine-methyl ester (L-NAME) and NG-monomethyl-L-arginine (L-NMMA) (Guo and Crawford 2005). Xanthin oxidoreductase and polyamine/hydroxylamine-dependent NO production has also been reported in plants (reviewed by Mur et al. 2013). NO content of tissues can be elevated by the application of exogenous NO donors (e.g., diethylamine nitric oxide, DEANO; 2,2'-(hydroxynitrosohydrazono)bis ethane DETA/ NO; $S$-nitrosoglutathione, GSNO; sodium nitroprusside, SNP) which cause different concentration and time-dependent increases in tissue NO level (Mur et al. 2013).

Various salt treatments enhanced NO production in many plant species and plant organs (Fig. 13.2). NO accumulation was observed in roots (Xie et al. 2008, Xu et al. 2011a), leaves (Tanou et al. 2012), calli (Zhao et al. 2004, 2007; Vital
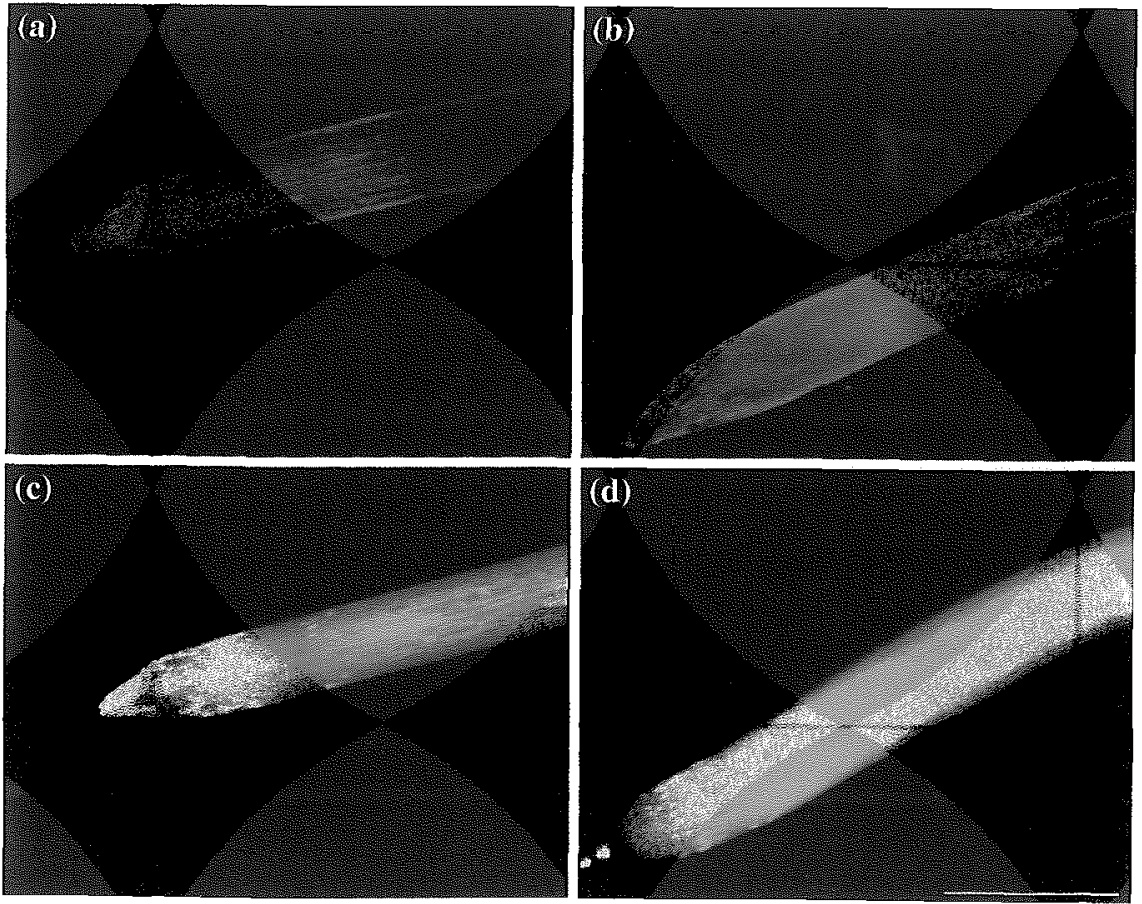

Fig. 13.2 Changes in NO levels in the apical segments of tomato roots treated with $250 \mathrm{mM} \mathrm{NaCl}$ for 0 (a), I (b), 3 (c), and 6 (d) hours. NO was visualized using 4-amino-5-methylamino-2', 7'difluorofluorescein diacetate (DAF-FM DA). White bars represent $1 \mathrm{~mm}$ (Poór et al, unpublished reculte) 
et al. 2008; Wang et al. 2009; Sun et al. 2010; Yang et al. 2010), cell suspension cultures (Banu et al. 2010; Poór and Tari 2011), and protoplasts (Gémes et al. 2011) after $\mathrm{NaCl}$ treatment. Zhang et al. (2006) observed time-dependent changes in NO production in Zea mays leaves after treatment with $100 \mathrm{mM} \mathrm{NaCl}$. NO accumulation displayed a maximum after $2 \mathrm{~h}$ of $\mathrm{NaCl}$ exposure and after $8 \mathrm{~h}$ it decreased back to the control level. A similar tendency was observed in Arabidopsis thaliana calli (Wang et al. 2009) and Solanum lycopersicum cell suspension culture (Poór et al. 2013). Rapid NO and ROS productions were detected in calli of a highly resistant species, Populus euphratica during salt stress(Sun et al. 2010). These results suggested that the $\mathrm{NaCl}$-induced $\mathrm{NO}$ production was transient and NO levels increased significantly in parallel with ROS production in the first minutes and hours of salt treatment. Unfortunately, in most of the studies, the production of $\mathrm{NO}$ was determined only at one time-point after the salt exposure and there was no time-dependent analysis of NO and other reactive nitrogen species (RNS) such as peroxinitrite $\left(\mathrm{ONOO}^{-}\right)$during salt stress in parallel with the determination of various types of reactive oxygen forms, which can determine the fate of the cells later.

Numerous studies reported that NO could be synthesized by NOS-like activity as well as by NR after salt treatment. $\mathrm{NaCl}$-induced $\mathrm{NO}$ synthesis was inhibited by the NOS inhibitor L-NAME in Atriplex centralasiatica (Xu et al. 2011a), Olea europaea (Valderrama et al. 2007), Phragmites communis (Zhao et al. 2004), and Populus euphratica (Zhang et al. 2007). In contrast, Liu et al. (2007) reported that NO production, induced by $100 \mathrm{mM} \mathrm{NaCl}$, was not affected by L-NAME in Phaseolus vulgaris. In Arabidopsis thaliana, Zhao et al. (2007a) observed a reduced quantity of the NOAl protein and decreased NO levels after being exposed to $100 \mathrm{mM} \mathrm{NaCl}$ for $2 \mathrm{~h}$. AtNOAl (AtNOSI) was identified as a putative Arabidopsis NOS gene, because these Arabidopsis mutants were defective in NO accumulation in the roots (Guo et al. 2003), but later it was found that AtNOSI had no NOS activity in vitro. Thus, AtNOSI was renamed as NO-associated protein 1 (AtNOAI), which is a chloroplast-targeted GTPase essential for ribosome assembly (Moreau et al. 2008). On the other hand, the NR-mediated NO production was involved in salt stress response of Nicotiana tabacum (Charrier et al. 2013) and Olea europaea (Valderrama et al. 2007). These discrepancies could be explained by the differences in the salt concentrations applied, the duration of salt exposure, the plant species and tissues, and the age of plants in the experiments. It can be concluded that the origin of NO may vary from species to species and from tissue to tissue that show different sensitivities to increased $\mathrm{Na}^{+}$concentrations.

\subsection{NO in Signal Transduction}

The role of NO in the regulation of gene expression was revealed first in largescale transcriptional analysis of Arabidopsis thaliana by DNA-microarrays (Grün 
down-regulated in Arabidopsis roots (Parani et al. 2004). These genes are involved in signal transduction, cellular transport, photosynthesis, abiotic stress response, and disease resistance. The transcript levels of signal transduction components such as defence-related MAP kinases, WRKY transcription factors, and ERE (ethylene response element) binding proteins, dehydration responsive element binding proteins (DREB1 and DREB2), oxidative stress-related proteins (glutathione transferases, $A B C$ transporters), mitochondrial $(A O X I)$ or chloroplastic proteins, e.g., $S O D$ and $A P X$, and genes participating in iron homeostasis (ferritin) were enhanced by SNP (reviewed by Grün et al. 2006).

NO participates in multiple signaling pathways in plants (Lamattina et al. 2003; Corpas et al. 2004; Lamotte et al. 2005; Besson-Bard et al. 2008; Distefano et al. 2008; Moreau et al. 2010; del Rio 2011). It interacts with the iron atom of the hem moiety in guanylate cyclase (GC), which, in this activated form, produces the second messenger cyclic GMP (cGMP) and interferes with the activity of protein kinases (PKs). A novel soluble GC that binds NO and generates cGMP has been recently described in Arabidopsis (Mulaudzi et al. 2011). NO increases cytosolic $\mathrm{Ca}^{2+}$ levels, which modulate the activity of $\mathrm{Ca}^{2+}$-dependent protein kinases (CDPKs) or mitogen-activated protein kinases (MAPKs). Phosphatidic acid (PA), a lipid-derived second messenger is also involved in NO signaling. NO interferes with various steps of ROS-induced signaling and acts as an important mediator of $\mathrm{H}_{2} \mathrm{O}_{2}$-induced cell death (Wang et al. 2013).

NO can modulate protein structure or activity through $S$-nitrosylation of specific cysteine residues, through nitration of specific tyrosines or through binding to metal cofactors of the enzymes. $S$-nitrosylation of proteins, a reversible posttranslational modification, occurs when a cysteine thiol in special position of the protein reacts with NO in the presence of an electron acceptor. The formation of $S$-NO bonds affects the function of a wide range of proteins, e.g., of those participating in signal transduction, such as tyrosine phosphatase $1 \mathrm{~B}(\mathrm{Li}$ and Whorton 2003), nuclear factor-kB kinase (Reynaert et al. 2004), or R2R3-MYB class transcription factors (Palmieri et al. 2008). S-nitrosylation of proteins participating in auxin and salicylic acid signaling has been excellently reviewed recently by Astier et al. (2012). NO in the presence of $\mathrm{O}_{2}$ can react with GSH to form $S$-nitrosoglutathione (GSNO), a reactive nitrogen form, which is a long-distance signaling molecule and a natural reservoir of $\mathrm{NO}$.

NO is able to react with various forms of ROS, e.g., with superoxide generating $\mathrm{ONOO}^{-}$and thus can regulate the redox status of the cell. Peroxynitrite is a strong oxidant, thus may target and inhibit cysteine-containing thiols, such as tyrosine phosphatases (Spoel et al. 2010). Peroxynitrite can react with tyrosine and tryptophan residues yielding 3-nitrotyrozine and nitrotryptophane (Vandelle and Delledonne 2011). Tyrosine nitration can change the function of proteins, and it may promote or inhibit the activity of enzymes. Tyrosine nitration may also interfere with signal transduction because the nitration of specific tyrosines prevents the phosphorylation of the regulatory proteins (Corpas et al. 2013).

Salt stress disrupts the equilibrium between NO production and elimina- 
as a messenger and effector molecule can induce both cell death and salt stress tolerance, which depends on a variety of factors, such as cell type, cellular redox status, and the flux and dose of the local NO concentration (Wang et al. 2010b).

\subsection{NO and Salt Tolerance}

The NO donor SNP enhanced the salt tolerance in many plant species. SNP increased germination, and root- and shoot growth under salinity stress as compared to the $\mathrm{NaCl}$-treated controls in various plant species.

Osmotic stress tolerance induced by the application of an NO donor is associated with an enhanced RWC in several species under high salinity (Sheokand et al. 2010; Zeng et al. 2011; Khan et al. 2012).

NO application significantly enhanced the $\mathrm{NaCl}$-induced osmotic stress tolerance via the accumulation of osmoprotectants such as glycine betaine, soluble sugars, or proline (Pro). Khan et al. (2012) found that SNP treatment increased the glycine betaine content in Brassica juncea leaves under salt stress. Enhanced soluble sugar content was found in Triticum aestivum seedlings (Zheng et al. 2009) and Solanum lycopersicum (Wu et al. 2011) after pre-treatment with the NO donor SNP under salt stress, which ameliorated the $\mathrm{NaCl}$-induced osmotic stress component.

The NO donor induced the accumulation of Pro by enhancing the activities of $\Delta^{1}$-pyrroline-5-carboxylate synthetase (P5CS), the enzyme catalyzing the rate limiting step of Pro biosynthesis, and by inhibiting the activity of the catabolic enzyme, Pro dehydrogenase (ProDH) in Triticum aestivum (Ruan et al. 2004b). Similarly, Pro was found to accumulate after SNP treatment in Arabidopsis thaliana (Zhang et al. 2010), Brassica juncea (Khan et al. 2012), Kosteletzkya virginica (Guo et al. 2009), and Solanum lycopersicum (Wu et al. 2011) under salt stress that enhanced tolerance to high salinity. In contrast, SNP decreased the Pro content in Brassica juncea (Zeng et al. 2011) and in Brassica rapa (López-Carrión et al. 2008). In the latter case, the NO donor did not change the activity of the biosynthetic enzyme, $\Delta$-1-pyrroline-5-carboxylate reductase (P5CR), but increased the activity of omithine- $\delta$-aminotransferase ( $\delta$-OAT) implicated also in Pro biosynthesis under salt stress. SNP together with $100 \mathrm{mM} \mathrm{NaCl}$ induced a significant rise in the activity of ProDH as compared to salt treatment suggesting that an increased Pro degradation contributed to low proline level in this species.

Salt stress increased the permeability of membranes, which can be partially prevented by the use of an NO donor leading to increased viability of cells. Accordingly, SNP decreased the membrane leakage in Cicer arietinum (Sheokand et al. 2010), Phragmites communis (Zhao et al. 2004), Triticum aestivum (Ruan et al. 2002), Zea mays (Zhang et al. 2006), and Brassica juncea (Khan et al. 2012).

The ionic effect of salt stress and the decrease in optimal $\mathrm{K}^{+} / \mathrm{Na}^{+}$ratio can also be mitigated by the use of NO donors. Higher NO levels correlated with higher $\mathrm{K}^{+} / \mathrm{Na}^{+}$ratios in Arabidonsis thaliang (Wang et al 2009) Braccica iuncea (Khan 
et al. 2012), Brassica rapa (López-Carrión et al. 2008), Kosteletzkya virginica (Guo et al. 2009), Phragmites communis (Zhao et al. 2004), Populus euphratica (Zhang et al. 2007), and Triticum aestivum (Ruan et al. 2004a; Zheng et al. 2009). Zhao et al. $(2007 \mathrm{a}, \mathrm{b})$ found that due to the reduced NO levels, Atnoal mutants displayed lower $\mathrm{K}^{+} / \mathrm{Na}^{+}$ratios in their shoots than wild-type plants under salt stress. These results confirm the positive effect of $\mathrm{NO}$ in maintaining the optimal $\mathrm{K}^{+} / \mathrm{Na}^{+}$ratios. In contrast, SNP had no effect on the osmotic potential and on the concentrations of $\mathrm{Na}^{+}, \mathrm{K}^{+}, \mathrm{Cl}^{-}$, and $\mathrm{NO}_{3}{ }^{-}$in the halophyte Suaeda salsa shoots (Song et al. 2009). The NO donor SNP enhanced the activities of PM and vacuolar $\mathrm{H}^{+}$-ATPases as well as that of vacuolar $\mathrm{H}^{+}$-PPase in Arabidopsis thaliana calli (Wang et al. 2009), cucumber (Shi et al. 2007), reed (Zhao et al. 2004), wheat (Ruan et al. 2004a; Xie et al. 2008), and maize tissues (Zhang et al. 2006) under salt stress. SNP treatment also enhanced the contents of other ions such as $\mathrm{Ca}^{2+}$ in Brassica juncea (Khan et al. 2012) and Phragmites communis (Zhao et al. 2004) under salinity. In wheat leaves, $\mathrm{Ca}^{2+}$ accumulation has been associated with increased Pro content on NO donor treatment (Ruan et al. 2004b).

Application of exogenous NO donor can also enhance salt tolerance by alleviating oxidative damage. SNP decreased the salt stress-induced harmful lipid peroxidation, malondialdehyde (MDA) content or the level of thiobarbituric acid reactive substances (TBARS) in Atriplex centralasiatica (Xu et al. 2011a), Brassica juncea (Zeng et al. 2011; Khan et al. 2012), Brassica rapa (López-Carrión et al. 2008), Cicer arietinum (Sheokand et al. 2008, 2010), Cucumis sativus (Shi et al. 2007; Lin et al. 2012a, b), Glycine max (Simaei et al. 2011), Hordeum vulgare (Li et al. 2008), Kosteletzkya virginica (Guo et al. 2009), Solanum lycopersicum (Wu et al. 2011), and Triticum aestivum (Ruan et al. 2002; Zheng et al. 2009; Hasanuzzaman et al. 2011; Xu et al. 2011 b).

$\mathrm{NO}$ can scavenge $\mathrm{H}_{2} \mathrm{O}_{2}$ and can protect plant cells from oxidative damage under salt stress by increasing the activity of antioxidative enzymes although their activities can be affected differently. NO donors decreased the salt-induced ROS production and activated SOD, peroxidases such as APX and GPX, CAT, and GR in various plant species. SNP promoted SOD-, POD-, and APX activities in Brassica juncea (Zeng et al. 2011; Khan et al. 2012), Populus euphratica (Sun et al. 2010), and Cicer arietinum plants (Sheokand et al. 2010). In contrast, higher activities of POX, APX, and GR were observed in the NO-deficient Atnoal plants, and these mutants also showed lower activities of SOD and CAT than wild-type plants under $\mathrm{NaCl}$ stress (Zhang et al. 2010). $0.05 \mathrm{mM}$ of SNP increased the activity of APX, whereas it decreased that of SOD and POD, and did not affect the activity of CAT in the roots of Phaseolus vulgaris plants exposed to high salinity (Liu et al. 2007). The NO donor SNP can also control the level of non-enzymatic antioxidants, such as those of ascorbate or glutathione. SNP treatments increased the reduced form of both metabolites and elevated the ratios of GSH/GSSG and ASC/DHA (Sheokand et al. 2010; Hasanuzzaman et al. 2011; Wu et al. 2011; Lin et al. 2012a). In other species such as Gossypium hirsutum, the NO donor decreased APX- and GR activity under salt stress, but CAT activity was not differenf from the salt-treated controls (Vital ef al 2008 ) 
The positive effect of exogenous NO on photosynthesis is well demonstrated in rice (Uchida et al. 2002). The maximal photochemical efficiency of photosystem II (Fv/Fm) decreased in WT and Atnoal mutant of Arabidopsis under salt stress, but the extent was higher in the mutant (Zhao et al. 2007a, b). Wu et al. (2010) observed that in salt-stressed plants, the NO donor attenuated the decrease in stomatal conductance $\left(\mathrm{g}_{\mathrm{s}}\right)$, transpiration rate $(\mathrm{E})$, leaf chlorophyll content, net $\mathrm{CO}_{2}$ fixation rate $\left(\mathrm{P}_{\mathrm{N}}\right)$, the ratio of variable to maximum fluorescence $(\mathrm{Fv} / \mathrm{Fm})$, relative electron transport rate (ETR), the effective quantum efficiency of photosystem II (PS II) reaction centers $\left(\mathrm{Fv}^{\prime} / \mathrm{Fm}^{\prime}\right)$, the photochemical quenching coefficient $(\mathrm{qP})$, and counteracted the increase in non-photochemical quenching coefficient (qN) in tomato plants. SNP decreased the salt-induced loss of chlorophyll content in Arabidopsis thaliana (Zhang et al. 2010), Brassica juncea (Khan et al. 2012), Citrus aurantium (Tanou et al. 2012), Triticum aestivum (Ruan et al. 2002, 2004a) and Zea mays (Zhang et al. 2006).

Moreover, exogenous NO treatment affects the stress hormone levels under salt stress. The concentration of the stress hormone abscisic acid (ABA) increased after SNP treatment in the leaves of wheat seedlings (Ruan et al. 2004b) but ethylene production decreased in the wild type but not in ethylene receptor mutant, etrl-3 Arabidopsis callus cultures (Wang et al. 2010c).

Protein nitration and $S$-nitrosylation are also involved in acclimation to salinity stress (Valderrama et al. 2007; Fares et al. 2011; Tanou et al. 2012). Tanou et al. (2009) reported that some proteins undergo a post-translational regulation. through either oxidation and/or $S$-nitrosylation in citrus plants exposed to salinity. These authors found that both $\mathrm{H}_{2} \mathrm{O}_{2}$ and SNP pretreatments before salt stress alleviated the salinity-induced protein carbonylation and caused the accumulation of $S$-nitrosylated proteins in the leaves. These results indicate an overlap between $\mathrm{H}_{2} \mathrm{O}_{2-}$ and $\mathrm{NO}$-mediated protein modifications in citrus plants during the acclimation to salinity.

Not only Pro but also polyamine contents changed significantly under salt stress. NO donor caused an increase in Spm content, (Spd + Spm)/Put ratio, and PAO activity in cucumber plants (Fan et al. 2010). This increase in Spm content may play a role in the protection against high salinity-induced damage (Yamaguchi et al. 2006).

\subsection{NO- and Salt-induced Programmed Cell Death}

NO is involved in plant PCD induction as a messenger and an effector molecule (Wang et al. 2010b) but in contrast to the $\mathrm{H}_{2} \mathrm{O}_{2}$-triggered PCD (Dat et al. 2003; Gechev et al. 2006), NO alone is not able to kill the cells (Zago et al. 2006). NO also plays a fundamental role in senescence and HR (Lin et al. 2012a, b), and it acts in strong partnership with $\mathrm{H}_{2} \mathrm{O}_{2}$ during the induction of PCD (Delledonne et al. 2001; De Pinto et al. 2002). Moreover, it can react with superoxide generating toxic $\mathrm{ONOO}^{-}$(Delledonne ef al $20 \mathrm{nI}$ ) which at hioh concentration initiates 
cell death (Gupta and Igamberdiev 2011). Time-course experiments indicated that $\mathrm{O}_{2}-$ rather than $\mathrm{H}_{2} \mathrm{O}_{2}$ functions in synergism with $\mathrm{NO}$ to trigger the PCD program (Blokhina and Fagerstedt 2010; Arasimowicz-Jelonek et al. 2012).

In salt-tolerant Populus euphratica callus cells, the antioxidant enzymes were induced by the rapid increase in NO and ROS production after salt treatment, thus the cells could maintain high $\mathrm{K}^{+} / \mathrm{Na}^{+}$ratios. NO and ROS productions exhibited only small changes in salt-sensitive Populus popularis, therefore the cells displayed low $\mathrm{K}^{+} / \mathrm{Na}^{+}$ratio and cell viability (Sun et al. 2010). Zhao et al. (2007a, b) demonstrated that a NOS inhibitor or a NO scavenger reduced endogenous NO levels and enhanced $\mathrm{NaCl}$-induced decrease in $\mathrm{K}^{+} / \mathrm{Na}^{+}$ratio in Arabidopsis. Moreover, the decrease in the $\mathrm{K}^{+}$concentration and the increase in that of $\mathrm{Na}^{+}$ were greater in Atnoal mutant than in wild-type plants under salt stress due to the reduced endogenous NO levels. Atnoal plants exhibited a much higher increase in $\mathrm{H}_{2} \mathrm{O}_{2}$ contents than wild types in response to $\mathrm{NaCl}$ treatments, which indicates that endogenous NO can effectively attenuate oxidative stress. The ion disequilibrium was the primary cause of cell death in the apical region of primary roots in wild-type and sos 1 Arabidopsis mutant but the effect was much more pronounced in the mutant plants. Salt-induced PCD displayed the hallmarks of both apoptosisand lysigenous-type PCD, the nuclear fragmentation, and DNA ladder as well as high vacuolation of cells in the elongation/differentiation zones. The authors suggested that the elimination of primary roots and the differentiation of the secondary roots in plants exposed to salt shock appear to be an adaptive mechanism (Huh et al. 2002).

Both enhanced and reduced $\mathrm{Ca}^{2+}$ levels were reported in plants exposed to high salinity (Halperin et al. 1997; Rabie and Almadini 2005; Yang et al. 2007), which can alleviate salt injury or may be involved in signal transduction. Gao et al. (2004) found an elevated steady-state level of the cytoplasmic $\mathrm{Ca}^{2+}$ and an increased apoplastic $\mathrm{Ca}^{2+}$ concentration in Arabidopsis roots during salt stress. Other authors found a significantly increased $\mathrm{Ca}^{2+}$ content on dry mass basis in tomato suspension cells when exposed to lethal concentrations of $\mathrm{NaCl}$ (Poór et al. 2012).

Overproduction of NO or the other RNS can cause toxic symptoms, called "nitrosative stress." This, in combination with oxidative stress due to overproduction of ROS, can lead to a "point of no return" in PCD initiation. The generation of RNS and ROS takes place in various cell compartments and depending on the half-life, transport properties, and concentrations of molecular species, they can act synergistically or can scavenge one another.

PM NADPH oxidase, the enzyme that catalyzes one electron reduction of $\mathrm{O}_{2}$ to $\mathrm{O}_{2}{ }^{-}$, has been described as an important source of apoplastic $\mathrm{H}_{2} \mathrm{O}_{2}$ after dismutation of superoxide during salt stress (Yang et al. 2007). Treatment with $150 \mathrm{mM}$ $\mathrm{NaCl}$ or the NO donor SNP increased the activity of the PM NADPH oxidase and the generation of $\mathrm{H}_{2} \mathrm{O}_{2}$ in Populus euphratica callus cultures. Moreover, it was observed that the application of NMMA, a NOS inhibitor, strongly blocked the plasma membrane NADPH oxidase activity and the production of $\mathrm{H}_{2} \mathrm{O}_{2}$ under salt strece in these ticsues (Thano at al ONO7) Tt was found hy nther authore that 
$S$-nitrosylation of the Cys- 890 of the protein reduced the activity of NADPH oxidase in the leaves of Arabidopsis in response to an avirulent pathogen (Yun et al. 2011), suggesting that NO might regulate ROS production by this enzyme in various ways.

Chloroplasts, the important sources of ROS under salt stress, are capable of both Arg- and nitrite-dependent NO generation (Jasid et al. 2006) suggesting that they contribute to nitrosative and oxidative stresses very effectively. Chloroplastic proteins such as oxygen-evolving enhancer protein 1 and 2,-small and large subunits of Rubisco, Rubisco activase, plastocyanin, and phosphoribulokinase are targets of $S$-nitrosylation in potato (Kato et al. 2012). Photosynthesis-related proteins involved in the Calvin-Benson cycle were largely targeted by carbonylation, nitration, and nitrosylation in citrus plants primed with $\mathrm{H}_{2} \mathrm{O}_{2}$ or SNP prior to salt stress (Tanou et al. 2012). The authors discussed the importance of these posttranslational modifications in the acclimation to high salinity. In contrast, nitration of specific tyrosine of D1 protein (PSBA) of photosystem II leads to the dissociation of the PS II dimers and PS II-LHCII supercomplexes during high light stress (Galetskiy et al. 2011). Carbonic anhydrase in sunflower (Chaki et al. 2013) and chloroplastic glycerinaldehyde-3-phosphate dehydrogenase in Arabidopsis (Lozano-Juste et al. 2011) were also among the Tyr-nitrated proteins under stress conditions that showed reduced activity.

Peroxisomes are sites of the L-Arg-dependent NO production and contain CATand $\mathrm{H}_{2} \mathrm{O}_{2}$-producing flavin oxidase that participates in photorespiration (del Río 2011). Peroxisomes in Arabidopsis were also shown to be required for the accumulation of NO in the cytosol during salt stress (Corpas et al. 2009).

The peroxisomal enzyme, CAT, and APX activities were inhibited by NO (Clark et al. 2000). Since glycine hydroxymethyltrasferase, a mitochondrial enzyme participating in photorespiration, was also down-regulated by salt stress and NO (Kilian et al. 2007), it can be assumed that nitrosative stress contributes to salt stress-induced inhibition of photorespiration. The catabolism of PAs by DAO or $\mathrm{PAO}$ enhanced $\mathrm{H}_{2} \mathrm{O}_{2}$ production which was suggested to be a signal leading to PCD in salt-stressed tobacco tissues. In these experiments, the authors demonstrated that spermidine was secreted and oxidized by PAO in the apoplast upon salt stress (Moschou et al. 2008), but other PAO isoenzymes (AtPAO2, AtPAO3, and AtPAO4) were localized to peroxisomes (Kamada-Nobusada et al. 2008) or to the vacuole (Cervelli et al. 2004).

Salt stress-induced PCD is mediated by the status of the mitochondrial PTP and ROS production in tobacco protoplasts. The cells displayed several morphological hallmarks of apoptosis, such as nuclear DNA degradation, formation of PTP on mitochondrial membrane, and a decrease in the mitochondrial membrane potential $\left(\Delta \psi_{\mathrm{m}}\right)$. Externally applied ascorbic acid prevented the decrease in $\Delta \psi_{\mathrm{m}}$ and the increase in ROS production, suggesting that ROS formation plays a key regulatory role in PCD initiation. ATP synthesis was reduced in plant mitochondria by the inhibition of cytochrome oxidase activity (Yamasaki et al. 2001). In Arabidopsis plants, NO induced the de-polarization of $\psi_{\mathrm{m}}$ and the release of cyt $c$ from the 
NO effect depends on the physiological status of plant cells (Zottini et al. 2002). Since the role of cyt $c$ may be different in plant and animal PCDs, other apoptosisinducing factors can also be released from the mitochondrial intermembrane space (reviewed by Reape and McCabe 2010).

Rice nitric oxide excess (noel) mutant was identified due to high $\mathrm{NO}$ and $S$-nitrosothiol contents of plants. The map-based cloning revealed that NOEI encoded OsCATC, so the plants were catalase deficient (Lin et al. 2012b). These plants had higher $\mathrm{H}_{2} \mathrm{O}_{2}$ levels under high light, which consequently promoted NO production via the activation of NR. The plants exhibited a cell death phenotype under high light intensity and the accumulation of NO promoted the $S$-nitrosylaton of glyceraldehyde-3-phosphate (GAPDH) and thioredoxin (TRX), the two enzymes, which are involved in $S$-nitrosylation-regulated cell death in animal cells (Wang et al. 2013). TRX is presumed to be $S$-nitrosylated in the active site, which inhibits its oxido-reductase function (Sumbayev 2003). Since TRX is a key modulator of cell redox status, this post-translational modification promotes apoptosis. GAPDH has also been shown to be $S$-nitrosylated, which decreases its enzymatic activity (reviewed by Astier et al. 2012). The NtGAPCb isoform of this protein constitutively interacts with NtOSAK (Nicotiana tabacum osmotic stress-activated protein kinase) both in the cytosol and the nucleus. This kinase was found to be phosphorylated and thus activated in plant tissues during salt stress. The $S$-nitrosylation of NtGAPCb had no influence on the interaction with NtOSAK or on its kinase activity but prevented the nuclear localization of the complex (Burza et al. 2006). In Arabidopsis peroxiredoxin IIE (PerIIE), an enzyme involved in the maintenance of redox status of the cells possesses a peroxynitrite reductase activity, thus it can control $\mathrm{ONOO}^{-}$levels. PerIIE activity is inhibited by $S$-nitrosylation, suggesting a regulatory effect of NO on the strength of nitrosative stress (Romero-Puertas et al. 2007).

It has been shown recently that short-term salt stress induces apoptosis-like, whereas long-term salt stress non-apoptotic PCD (Andronis and RoubelakisAngelakis 2010). In both cases, the execution of cell death is mediated by the induction of cysteine proteases, some of them showing caspase-like activities. Caspase-like activity seems to be activated by $\mathrm{K}^{+}$deficiency in plant cells (Demidchik et al. 2010), which is in good correlation with the induction of cysteine protease activity in salt-stressed plants (Kovács et al. 2012).

Long-term salt stress increased $\mathrm{H}_{2} \mathrm{O}_{2}$ and $\mathrm{NO}$ productions, resulted in elevated lipid peroxidation, caspase-like activity, and cell death in maize roots. However, an exogenously applied NO donor, DETA/NO, reversed the detrimental effect of salt stress and reduced the salt-induced oxidative stress and caspase-like activity in maize tissues (Keyster et al. 2012). Plant metacaspases are considered to be ancestors of metazoan caspases, their maturation involves an autocatalytic processing of the zymogen form and their active participation in PCD. The zymogen form of AtMC9, a member of Arabidopsis metacaspase family, was constitutively $S$-nitrosylated in vivo which kept the enzyme in an inactive form. However, the active, processed enzyme was no longer a target of $S$-nitrosylation (Relenohi ef a1. 2007). 
Poór et al. (2013) found that NO production by tomato cell suspension increased in the first hour, but did not change later at the lethal concentration of $\mathrm{NaCl}$. In contrast, ROS production increased significantly for $6 \mathrm{~h}$ during the experimental period. Salt-induced ROS production was controlled by ethylene, which enhanced the percentage of dead cells. The salt stress caused a loss of the membrane semipermeability, chromatin condensation, cell shrinkage, and DNA fragmentation in the cells. The effect of specific inhibitors confirmed that the $\mathrm{Ca}^{2+}$ signaling, MAPKs, and cysteine proteases are involved in salt stress-induced PCD in tomato suspension cultures.

\subsection{Conclusion and Perspectives}

Despite the fact that the knowledge concerning the role of NO in higher plants under salt stress has increased considerably in the recent ten years, there are still many gaps in comprehending the mode of NO action that controls the salt stressinduced cell death or the acclimation of plants to saline environments.

Salt stress enhanced the NO production of tissues in many plant species. Unfortunately, most of the authors determined NO accumulation only at one timepoint after salt exposure although the rise is transient and may vary from some minutes to few hours or days (Keyster et al. 2012). This NaCl-generated NO can be inhibited by NOS and NR inhibitors, suggesting that several NO-producing mechanisms can be activated in a time- and tissue-specific manner.

It can be concluded from several reports that the treatment with exogenous NO donors could alleviate the toxic effect of salt stress. The application of SNP increased the biomass, the contents of osmoprotectants such as glycine betaine, proline, and soluble sugars, and increased $\mathrm{RWC}$ and $\mathrm{K}^{+} / \mathrm{Na}^{+}$ratios under salt stress. SNP decreased the salt stress-induced lipid peroxidation, ROS production, activated the antioxidant enzymes such as SOD, POX, GPX, APX, CAT, GR, and DHAR, and enhanced the non-enzymatic antioxidant pools (ASA and GSH). The NO donor has also a positive effect on photosynthesis under high salinity. Unfortunately, in most of the experiments, the NO levels of the tissues have not been determined during the acclimation period after SNP treatment. Moreover, SNP can generate not only NO but highly toxic cyanide thus treatment with $0.5 \mathrm{mM}$ SNP caused PCD within $12 \mathrm{~h}$ in tobacco BY-2 cell suspensions (Vitecek et al. 2007).

NO-mediated $S$-nitrosylation and nitration of proteins may be involved in acclimation to salinity stress, but the enhancement of peroxynitrite-dependent Tyr nitration may shift the cells to the initiation of PCD (Corpas et al, 2013).

In plant tissues, $\mathrm{NO}$ and ROS produced during salt stress cooperate to trigger PCD (Fig. 13.3). The reaction of NO with superoxide radical leads to peroxynitrite, which is not essential in NO-mediated PCD. Moreover, $\mathrm{NO}$ and $\mathrm{H}_{2} \mathrm{O}_{2}$ can chemically react with each other producing singlet oxygen and hydroxyl radicals. These verv reactive radicals can induce fast cell death (Wang et al 2013 ) 


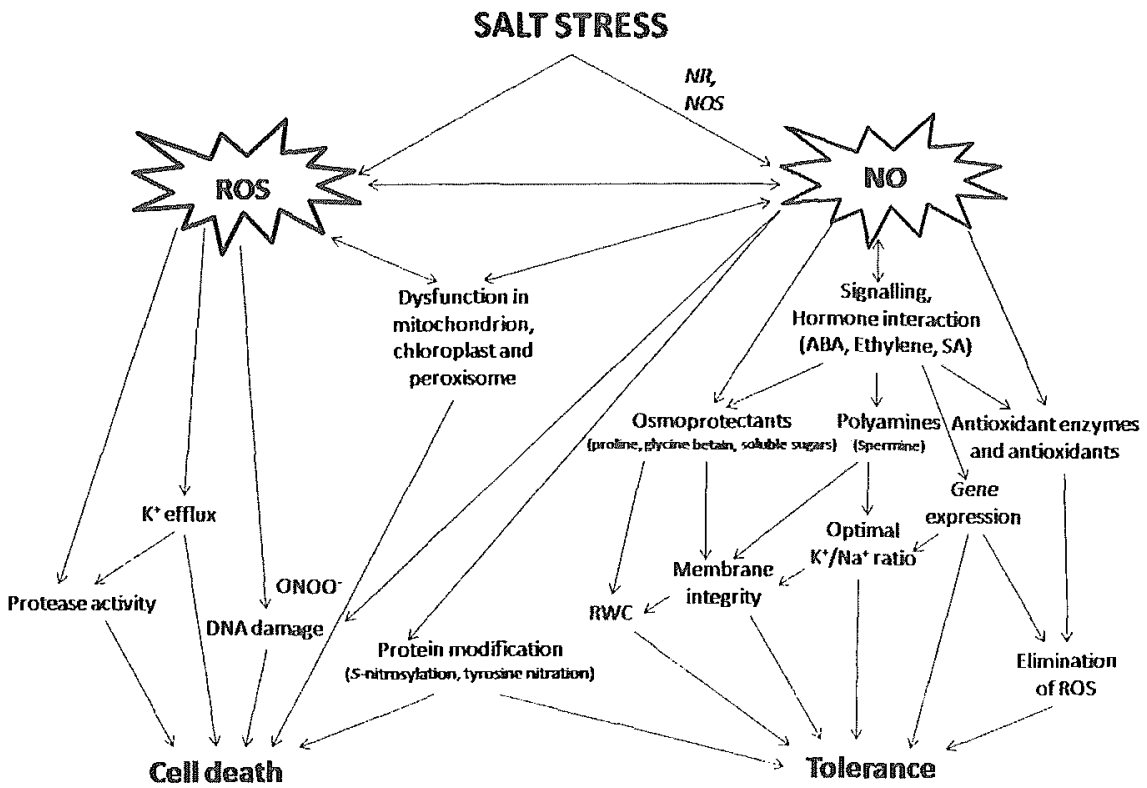

Fig. 13.3 The role of NO in salt-induced cell death and salt salt tolcrance

Although there are a number of experimental data on the physiological aspects of $\mathrm{NO}$-mediated alleviation of $\mathrm{NaCl}$-induced stress, our knowledge is imperfect concerning the changes in NO contents in parallel with those of individual species of RNS and ROS.

The NO-mediated signal transduction, the detailed investigation of NO-mediated post-translational protein modifications, and gene expression changes have been performed only in few species under lethal salt concentrations. To see whether these changes were due to the NO-dependent changes in the activity of the related enzymes or due to the NO-induced control of gene expression, further analyses have to be done.

The description of the specificity of the individual reactive nitrogen forms in the signal transduction of plant hormones accumulating under salt stress would also provide new insights into converging and diverging signaling pathways.

Finally, the comparison of salt stress-dependent changes in the transcriptome, proteome, and metabolome and the evaluation of the data by systems biology tools would be particularly useful in defining differences between salt-sensitive and salttolerant genotypes or between glycophytes and halophytes.

Acknowledgments We apologize to those colleagues whose work was not reviewed here. This work was supported by grants from the Hungarian Scientific Research Fund (OTKA K101243 and OTKA-PD112855). No conflict of interest is declared. 


\section{References}

Abdelkader AF, Aronsson H, Sundqvist C (2007) High salt stress in wheat leaves causes retardation of chlorophyll accumulation due to a limited rate of protochlorophyllide formation. Physiol Plant 130:157-166

Affenzeller MJ, Darehshouri A, Andosch A et al (2009) Salt stress-induced cell death in the unicellular green alga Micrasterias denticulate. J Exp Bot 60:939-954

Andronis EA, Roubelakis-Angelakis KA (2010) Short-term salinity stress in tobacco plants leads to the onset of animal-like PCD hallmarks in planta in contrast"to long-term stress. Planta $231: 437-448$

Arasimowicz-Jelonek M, Floryszak-Wieczorek J, Deckert J et al (2012) Nitric oxide implication in cadmium induced programmed cell death in roots and signaling response of yellow Iupine plants. Plant Physiol Biochem 58:124-134

Ashraf M, Harris PJC (2004) Potential biochemical indicators of salinity tolerance in plants. Plant Sci 166:3-16

Ashraf M (2009) Biotechnological approach of improving plant salt tolerance using antioxidants as markers. Biotec Advan 27:84-93

Astier J, Kulik A, Koen E et al (2012) Protein S-nitrosylation: what's going on in plants? Free Rad Biol Med 53:1101-1110

Balk J, Chew SK, Leaver CJ, McCabe PF (2003) The intermembrane space of plant mitochondria contains a DNase activity that may be involved in programmed cell death. Plant J $34: 573-583$

Banu MNA, Hoque MA, Watanabe-Sugimoto M et al (2010) Proline and glycinebetaine ameliorated $\mathrm{NaCl}$ stress via scavenging of hydiogen peroxide and methylglyoxal but not superoxide or nitric oxide in tobacco cultured cells. Biosci Biotech Biochem 74:2043-2049

Belenghi B, Romero-Puertas MC, Vercammen D et al (2007) Metacaspase activity of Arabidopsis thaliana is regulated by $S$-nitrosylation of a critical cysteine residue. J Biol Chem 282:1352-1358

Besson-Bard A, Pugin A, Wendehenne D (2008) New insights into nitric oxide signaling in plants. Annu Rev Plant Biol 59:21-39

Blokhina O, Fagerstedt KV (2010) Reactive oxygen species and nitric oxide in plant mitochondria: origin and redundant regulatory systems. Physiol Plant 138:447-462

Blumwald E (2000) Sodium transport and salt tolerance in plants. Curr Opin Cell Biol $12: 431-434$

Bright J, Desikan R. Hancock JT et al (2006) ABA-induced NO generation and stomatal closure in Arabidopsis are dependent on $\mathrm{H}_{2} \mathrm{O}_{2}$ synthesis. Plant $\mathrm{J} 45: 113-122$

Burza AM, Pękala I, Sikora J et al (2006) Nicotiana tabacum osmotic stress-activated kinase is regulated by phosphorylation on Ser-154 and Ser-158 in the kinase activation loop. J Biol Chem 281:34299-34311

Cacas JL, Diamond M (2009) Is the autophagy machinery an executioner of programmed cell death in plants? Trends Plant Sci 14:299-300

Cervelli M, Caro OD, Penta AD et al (2004) A novel C-terminal sequence from barley polyamine oxidase is a vacuolar sorting signal. Plant $\mathbf{J} 40: 410-418$

Chaki M, Carreras A, López-Jaramillo J et al (2013) Tyrosine nitration provokes inhibition of carbonic anhydrase ( $\beta$-CA) activity under high temperature stress. Nitric Oxide Biol Chem 29:30-33

Charrier A, Lelièvre E, Limani AM, Planchet E (2013) Medicago truncatula stress associated protein 1 gene (MtSAPI) overexpression confers tolerance to abiotic stress and impacts proline accumulation in transgenic tobacco. J Plant Physiol 170:874-877

Chaves MM, Flexas J, Pinheiro C (2009) Photosynthesis under drought and salt stress: regulation mechanisms from whole plant to cell. Ann Bot 1034:551-560

Chen X, Wang Y, Li J et al (2009) Mitochondrial proteome during salt stress-induced programmed cell death in rice. Plant Phvsiol Biochem $47: 407-415$ 
Clark D, Durner J, Navarre DA, Klessig DF (2000) Nitric oxide inhibition of tobacco catalase and ascorbate peroxidase. Mol Plant-Microbe Interact 13:1380-1384

Cona A, Rea G, Angelini R et al (2006) Functions of amine oxidases in plant development and defence. Trends Plant Sci 1 1:80-88

Corpas FJ, Barroso JB, Carreras A et al (2004) Cellular and subcellular localization of endogenous nitric oxide in young and senescent pea plants. Plant Physiol 136:2722-2733

Corpas FJ, Barroso JB, Carreras A et al (2006) Constitutive arginine-dependent nitric oxide synthase activity in different organs of pea seedlings during plant development. Planta 224:246-254

Corpas FJ, Hayashi M, Mano S et al (2009) Peroxisomes are required for in vivo nitric oxide accumulation in the cytosol following salinity stress of Arabidopsis plants. Plant Physiol 151:2083-2094

Corpas FJ, Leterrier M, Valderrama R, Airaki M, Chaki M, Palma JM, Barroso JB (2011) Nitric oxide imbalance provokes a nitrosative response in plants under abiotic stress. Plant Sci 181:604-611

Corpas FJ, Palma JM, Luis A, Barroso JB (2013) Protein tyrosine nitration in higher plants grown under natural and stress conditions. Front Plant Sci 4:29

Dassanayake M, Oh DH, Hong $\mathrm{H}$ et al (2011) Transcription strength and halophytic lifestyle. Trends Plant Sci 16:1-3

Delledonne M, Zeier J, Marocco A, Lamb C (2001) Signal interactions between nitric oxide and reactive oxygen intermediates in the plant hypersensitive disease resistance response. Proc Nat Acad Sci USA 98:13454-13459

Delledonne M (2005) NO news is good news for plants. Curr Opin Plant Biol 8:390-396

De Pinto MC, Tommasi F, De Gara L (2002) Changes in the antioxidant systems as part of the signaling pathway responsible for the programmed cell dealh activated by nitric oxide and reactive oxygen species in tobacco bright-yellow 2 cells. Plant Physiol 130:698-708

De Pinto MC, Locato V, De Gara L (2012) Redox regulation in plant programmed cell death. Plant, Cell Environ 35:234-244

del Rio LA, Corpas FJ, Barroso JB (2004) Nitric oxide and nitric oxide synthase activity in plants. Phytochemistry 65:783-792

del Río LA (2011) Peroxisomes as a cellular source of reactive nitrogen species signal molecules. Arch Biochem Biophys 506:1-11

Demidchik V, Cuin TA, Svistunenko D et al (2010) Arabidopsis root $\mathrm{K}^{+}$-efflux conductance activated by hydroxyl radicals: single-channel properties genetic basis and involvement in stress-induced cell death. J Cell Sci 123:1468-1479

Desikan R, Griffiths R, Hancock J, Neill S (2002) A new role for an old enzyme: nitrate reductase-mediated nitric oxide generation is required for abscisic acid-induced stomatal closure in Arabidopsis thaliana. Proc Nat Acad Sci USA 99:16314-16318

Dat JF, Pellinen R, Van De Cotte B et al (2003) Changes in hydrogen peroxide homeostasis trigger an active cell death process in tobacco. Plant J 33:621-632

Distefano AM, Garcia-Mata C, Lamattina L, Laxalt AM (2008) Nitric oxide-induced phosphatidic acid accunulation: a role for phospholipases $\mathrm{C}$ and $\mathrm{D}$ in stonatal closure. Plant, Cell Environ 31:187-194

Dutilleul C. Garmier M, Noctor G et al (2003) Leaf mitochondria modulate whole cell redox homeostasis set antioxidant capacity and determine stress resistance through altered signaling and diurnal regulation. Plant Cell Online 15:1212-1226

Enari M, Sakahira H. Yokoyama H et al (1998) A caspase-activated DNase that degrades DNA during apoptosis and its inhibitor ICAD. Nature 391:43-50

Fan HF, Du CX, Guo SR (2010) Nitric oxide enhances salt tolerance in cucumber seedlings by regulating free polyamine content. Environ Exp Bot 86:52-59

Fares A, Rossignol M. Peltier JB (2011) Proteomics investigation of endogenous $S$-nitiosylation in Arabidopsis. Biochem Biophys Res Commun 416:331-336

Flowers TJ (1974) Salt tolerance in Staaeda maritima (L.) Dum-comparison of mitochondria 
Foyer CH, Noctor G (2003) Redox sensing and signalling associated with reactive oxygen in chloroplasts, peroxisomes and mitochondria. Physiol Plant 119:355-364

Foyer CH, Noctor G (2005) Oxidant and antioxidant signalling in plants: a re-evaluation of the concept of oxidative stress in a physiological context. Plant Cell Environ 28:1056-1071

Galetskiy D, Lohscheider JN, Kononikhin AS et al (2011) Phosphorylation and nitration levels of photosynthetic proteins are conversely regulated by light stress. Plant Mol Biol 77:461-473

Gao D, Knight MR, Trewavas AJ et al (2004) Self-reporting Arabidopsis expressing pH and $\left[\mathrm{Ca}^{2+}\right]$ indicators unveil ion dynamics in the cytoplasm and in the apoplast under abiotic stress. Plant Physiol 134:898-908

Gechev TS, Van Breusegem F, Stone JM et al (2006) Reactive oxygen species as signals that modulate plant stress responses and programmed cell death. Bioessays 28:1091-1101

Gémes K, Poór P, Horváth E et al (2011) Cross-talk between salicylic acid and NaCl-generated reactive oxygen species and nitric oxide in tomato during acclimation to high salinity. Physiol Plant 142:179-192

Gill SS, Tuteja N (2010) Polyamines and abiotic stress tolerance in plants. Plant Sig Behav 5:26-33

Groppa MD, Benavides MP (2008) Polyamines and abiotic stress: recent advances. Amino Acids $34: 35-45$

Grü S, Lindermayr C, Sell S, Durner J (2006) Nitric oxide and gene regulation in plants. J Exp Bot 57:507-516

Gunawardena $\mathrm{AH}$ (2008) Programmed cell death and tissue remodelling in plants. J Exp Bot 59:445-451

Guo FQ, Okamoto M, Crawford NM (2003) Identification of a plant nitric oxide synthase gene involved in hormonal signalling. Science 302:100-103

Guo FQ, Crawford NM (2005) Arabidopsis nitric oxide synthasel is targeted to mitochondria and protects against oxidative damage and dark-induced senescence. Plant Cell Online 17:3436-3450

Guo Y, Tian Z, Yan D et al (2009) Effects of nitric oxide on salt stress tolerance in Kosteletzkya virginica. Life Sci J 6:67-75

Gupta KJ, Igamberdiev AU (2011) The anoxic plant mitochondrion as a nitrite: NO reductase, Mitochondrion 11:537-543

Halperin SJ, Kochian LV, Lynch JP (1997) Salinity stress inhibits calcium loading into the xylem of excised barley (Hordeum vulgare) roots. New Phytol 135:419-427

Hamilton EW, Heckathorn SA (2001) Mitochondrial adaptations to NaCl. Complex I is protected by antioxidants and small heat shock proteins whereas complex II is protected by proline and betaine. Plant Physiol 126: I 266-1274

Haro R, Bañuelos MA, Senn ME et al (2005) HKT1 mediates sodium uniport in roots. Pitfalls in the expression of $H K T 1$ in yeast. Plant Physiol 139:1495-1506

Hasegawa PM, Bressan RA, Zhu JK, Bohnert HJ (2000) Plant cellular and molecular responses to high salinity. Annu Rev Plant Biol 51:463-499

Hasanuzzaman M, Hossain MA, Fujita M (2011) Nitric oxide modulates antioxidant defense and the methylglyoxal detoxification system and reduces salinity-induced damage of wheat seedlings. Plant Biotech Rep 5:353-365

Hatsugai N, Kuroyanagi M, Yamada $\mathrm{K}$ et al (2004) A plant vacuolar protease VPE mediates virus-induced hypersensitive cell death. Science 305:855-858

He R, Drury GE, Rotari VI et al (2008) Metacaspase- 8 modulates programmed cell death induced by ultraviolet light and $\mathrm{H}_{2} \mathrm{O}_{2}$ in Arabidopsis. J Biol Chem 283:774-783

Horie T, Hauser F, Schroeder JI (2009) HKT transporter-mediated salinity resistance mechanisms in Arabidopsis and monocot crop plants. Trends Plant Sci 14:660-668

Huh GH, Damsz B, Matsumoto TK et al (2002) Salt causes ion disequilibrium-induced programmed cell death in yeast and plants. Plant J 29:649-659

Ihara-Ohori Y, Nagano M, Muto S et al (2007) Cell death suppressor Arabidopsis bax inhibitor-1 is associated with calmodulin binding and ion homeostasis. Plant Physiol 143:650-660

Jacoby RP, Taylor NL, Millar AH (2011) The role of mitochondrial respiration in salinity toler- 
Jasid S, Simontacchi M, Bartoli CG, Puntarulo S (2006) Chloroplasts as a nitric oxide cellular source. Effect of reactive nitrogen species on chloroplastic lipids and proteins. Plant Physiol 142: 1246-1255

Jiang Y, Yang B, Harris NS, Deyholos MK (2007) Comparative proteomic analysis of $\mathrm{NaCl}$ stress-responsive proteins in Arabidopsis roots. J Exp Bot 58:3591-3607

Jolivet Y, Pireaux JC, Dizengremel P (1990) Changes in properties of barley leaf mitochondria isolated from NaCl-treated plants. Plant Physiol 94:641-646

Jones A (2000) Does the plant mitochondrion integrate cellular stress and regulate programmed cell death? Trends Plant Sci 5:225-230

Joseph B, Jini D (2010) Salinity induced programmed cell death in plants: challenges and opportunities for salt-tolerant plants. J Plant Sci 5:376-390

Kamada-Nobusada T, Hayashi M, Fukazawa M et al (2008) A putative peroxisomal polyamine oxidase AtPAO4 is involved in polyamine catabolism in Arabidopsis thaliana. Plant Cell Physiol 49:1272-1282

Kato H, Takemoto D, Kawakita K (2012) Proteomic analysis of S-nitrosylated proteins in potato plant. Physiol Plant 148:371-386

Keyster M, Klein A, Ludidi N (2012) Caspase-like enzymatic activity and the ascorbate-glutathione cycle participate in salt stress tolerance of maize conferred by exogenously applied nitric oxide. Plant Sig Behav 7:349-360

Khan N, Siddiqui M, Mohammad MHF, Naeem M (2012) Interactive role of nitric oxide and calcium chloride in enhancing tolerance to salt stress. Nitric Oxide 27:210-218

Kilian J, Whitehead D, Horak J et al (2007) The AtGenExpress global stress expression data set: protocols evaluation and model data analysis of UV-B light drought and cold stress responses. Plant J 50:347-363

Kim HR, Lee GH, Ha KC et al (2008) Bax Inhibitor-1 is a pH-dependent regulator of $\mathrm{Ca}^{2+}$ channel activity in the endoplasmic reticulum. J Biol Chem 283:15946-15955

Kovács J, Poór P, Szepesi Á, Tari I (2012) Salt stress induced cysteine protease activities during programmed cell death in tomato. In: Rennenberg H, Reski R (eds) Book of abstracts, Plant biology congress freiburg 2012. FESPB and EPSO, Freiburg, Germany, p 365

Kroemer G, Galluzzi L, Brenner C (2007) Mitochondrial membrane permeabilization in cell death. Physiol Rev 87:99-163

Lamattina L, García-Mata C, Graziano M, Pagnussat G (2003) Nitric oxide: the versatility of an extensive signal molecule. Annu Rev Plant Biol 54:109-136

Lamotte O, Courtois C, Barnavon L et al (2005) Nitric oxide in plants: the biosynthesis and cell signalling properties of a fascinating molecule. Planta $221: 1-4$

Lambers H (2003) Introduction, dryland salinity: a key environmental issue in southern Australia. Plant Soil 257:5-7

Li SR, Whorton A (2003) Regulation of protein tyrosine phosphatase IB in intact cells by $S$-nitrosothiols. Arch Biochem Biophys 410:269-279

Li QY, Niu HB, Yin J et al (2008) Protective role of exogenous nitric oxide against oxidativestress induced by salt stress in barley (Hordeum vulgare). Colloids Surf B Biointerfaces $65: 220-225$

Lin J, Wang Y, Wang G (2006) Salt stress-induced programmed cell death in tobacco protoplasts is mediated by reactive oxygen species and mitochondrial permeability transition pore status. J Plant Physiol 163:731-739

Lin Y, Liu Z, Shi Q et al (2012a) Exogenous nitric oxide (NO) increased antioxidant capacity of cucumber hypocotyl and radicle under salt stress. Sci Hort 142:118-127

Lin A, Wang Y, Tang J et al (2012b) Nitric oxide and protein $S$-nitrosylation are integral to hydrogen peroxide-induced leaf cell death in rice. Plant Physiol 158:451-464

Liu Y, Wu R, Wan Q et al (2007) Glucose-6-phosphate dehydrogenase plays a pivotal role in nitric oxide-involved defense against oxidative stress under salt stress in red kidney bean roots. Plant Cell Physiol 48:511-522

López-Carrión AI, Castellano R, Rosales MA et al (2008) Role of nitric oxide under saline 
Lozano-Juste J, Colom-Moreno R, León J (2011) In vivo protein tyrosine nitration in Arabidopsis thaliana. J Exp Bot 62:3501-3517

Mehta P, Jajoo A, Mathur S, Bharti S (2010) Chlorophyll a fluorescence study revealing effects of high salt stress on photosystem II in wheat leaves. Plant Physiol Biochem 48:16-20

Miller G, Suzuki N, Ciftci-Yilmaz S, Mittler R (2010) Reactive oxygen species homeostasis and signalling during drought and salinity stresses. Plant Cell Environ 33:453 467

Moreau M, Lee GI, Wang Y et al (2008) AtNOS/AtNOA1 is a functional Arabidopsis thaliance cGTPase and not a nitric-oxide synthase. J Biol Chem 283:32957-32967

Moreau M, Lindermayr C, Durner J, Klessig DF (2010) NO synthesis and signaling in plantswhere do we stand? Physiol Plant 138:372-383

Moschou PN, Paschalidis KA, Delis ID et al (2008) Spermidine exodus and oxidation in the apoplast induced by abiotic stress is responsible for $\mathrm{H}_{2} \mathrm{O}_{2}$ signatures that direct tolerance responses in tobacco. Plant Cell Online 20:1708-1724

Mulaudzi T, Ludidi N, Ruzvidzo O et al (2011) Identification of a novel Arabidopsis thali. ana nitric oxide-binding molecule with guanylate cyclase activity in vitro. FEBS Lett 585:2693-2697

Munns R (2002) Comparative physiology of salt and water stress. Plant, Cell Environ 25:239-250 Munns R, Tester M (2008) Mechanisms of salinity tolerance. Ann Rev Plant Biol 59:651-681

Mur LAJ, Mandon J, Persijn S et al (2013) Nitric oxide in plants: an assessment of the current state of knowledge. AoB Plants 5. doi: 10.1093/aobpla/pls052

Neill SJ, Desikan R, Hancock JT (2003) Nitric oxide signalling in plants. New Phytol 159:11-35

Palmieri MC, Sell S, Huang $X$ et al (2008) Nitric oxide-responsive genes and promoters in Arabidopsis thaliana: a bioinformatics approach. J Exp Bot 59:177-186

Parani M, Rudrabhatla S, Myers R et al (2004) Microarray analysis of nitric oxide responsive transcripts in Arabidopsis. Plant Biotech J 2:359-366

Pardo JM, Cubero B, Leidi EO, Quintero FJ (2006) Alkali cation exchangers: roles in cellular homeostasis and stress tolerance. J Exp Bot 57:1181-1199

Poór P, Tari I (2011) Ethylene-regulated reactive oxygen species and nitric oxide under salt stress in tomato cell suspension culture. Acta Biol Szeged 55:143-146

Poór P, Szopkó D, Tari I (2012) Ionic homeostasis disturbance is involved in tomato cell death induced by $\mathrm{NaCl}$ and salicylic acid. In Vitro Cell Dev Biol-Plant 48:377-382

Poór P, Kovács J, Szopkó D, Tari I (2013) Ethylene signaling in salt stress and salicylic acidinduced programmed cell death in tomato suspension cells. Protoplasma 250:273-284

Rabie GH, Almadini AM (2005) Role of bioinoculants in development of salt-tolerance of Vicia faba plants under salinity stress. African J Biotech 4:210-222

Reape TJ, McCabe PF (2010) Apoptotic-like regulation of programmed cell death in plants. Apoptosis 15:249-256

Reynaert NL, Ckless K, Korn SH et al (2004) Nitric oxide represses inhibitory kB kinase through $S$-nitrosylation. Proc Nat Acad Sci USA 101(24):8945-8950

Rhodes D, Nadolska-Orczyk A, Rich PJ (2004) Salinity, osmolytes and compatible solutes. In: Läuchli A, Lïttige U (eds) Salinity: enviromment-plants-molecules. Springer, Netherlands, pp 181-204

Romero-Puertas MC, Campostrini N, Matte A et al (2007) S-nitrosylation of peroxiredoxin II E promotes peroxynitrite-mediated tyrosine nitration. Plant Cell 19:4120-4130

Ruan H, Shen W, Ye M, Xu L (2002) Protective effects of nitric oxide on salt stress-induced oxidative damage to wheat (Triticum aestivum L.) leaves. Chinese Sci Bulletin 47:677-681

Ruan HH, Shen WB, Xu LL (2004a) Nitric oxide modulates the activities of plasma membrane $\mathrm{H}^{+}-A T P a s e$ and PPase in wheat seedling roots and promotes the salt tolerance against salt stress. Acta Botanica Sinica 46:4 I5-422

Ruan HH, Shen WB, Xu LL (2004b) Nitric oxide involved in the abscisic acid induced proline accumulation in wheat seedling leaves under salt stress. Acta Botanica Sinica 46:1307-1315

Sang J, Jiang $M$, Lin F et al (2008) Nitric oxide reduces hydrogen peroxide accumulation involved in water stress-induced subcellular anti-oxidant defense in maize plants. J Integ Plant Rinl $50.231-243$ 
Shabala S (2009) Salinity and programmed cell death: unravelling mechanisms for ion specific signalling. J Exp Botany 60:709-712

Sheokand S, Kumari A, Sawhney V (2008) Effect of nitric oxide and putrescine on antioxidative responses under $\mathrm{NaCl}$ stress in chickpea plants. Physiol Mol Biol Plants 14:355-362

Sheokand S, Bhankar V, Sawhney V (2010) Ameliorative effect of exogenous nitric oxide on oxidative metabolism in $\mathrm{NaCl}$ treated chickpea plants. Braz J Plant Physiol 22:81-90

Shi Q. Ding F, Wang X, Wei M (2007) Exogenous nitric oxide protect cucumber roots against oxidative stress induced by salt stress. Plant Physiol Biochem 45:542-550

Siddiqui MH, Al-Whaibi MH, Basalah MO (2011) Role of nitric oxide in tolerance of plants to abiotic stress. Protoplasma 248:447-455

Siegal SM, Chen J, Kottenmeyer W et al (1982) Reduction in peroxidase in Cucumis, Brassica and other seedlings cultured in saline waters. Phytochem 21:539-542

Simaei M, Khavari-Nejad RA, Saadatmand S et al (2011) Effects of salicylic acid and nitric oxide on antioxidant capacity and proline accumulation in Glycine max $\mathrm{L}$. treated with $\mathrm{NaCl}$ salinity. Afr J Agric Res 6:3775-3782

Smith CA, Melino VJ, Sweetman C, Soole KL (2009) Manipulation of alternative oxidase can influence salt tolerance in Arabidopsis thaliana. Physiol Plant 137(4):459-472

Spoel SH, Tada Y, Loake GJ (2010) Post-translational protein modification as a tool for transcription reprogramming. New Phytol 186:333-339

Song J, Shi G, Xing S et al (2009) Effects of nitric oxide and nitrogen on seedling emergence, ion accumulation, and seedling growth under salinity in the euhalophyte Suada salsa. J Plant Nutr Soil Sci 172:544-549

Sumbayev VV (2003) $S$-nitrosylation of thioredoxin mediates activation of apoptosis signal-regulating kinase 1. Arch Biochem Biophys 415:133-136

Sun J, Li L, Liu M et al (2010) Hydrogen peroxide and nitric oxide mediate $\mathrm{K}^{+} / \mathrm{Na}^{+}$homeostasis and antioxidant defense in $\mathrm{NaCl}$-stressed callus cells of two contrasting poplars. Plant Cell Tiss Org Cul 103:205-215

Tanou G, Job C, Rajjou L et al (2009) Proteomics reveals the overlapping roles of hydrogen peroxide and nitric oxide in the acclimation of citrus plants to salinity. Plant J 60:795-804

Tanou G, Filippou P, Belghazi M et al (2012) Oxidative and nitrosative-based signaling and associated post-translational modifications orchestrate the acclimation of citrus plants to salinity stress. Plant J 72:585-599

Taylor NL, Tan YF, Jacoby RP, Millar AH (2009) Abiotic environmental stress induced changes in the Arabidopsis thaliana chloroplast, mitochondria and peroxisome proteomes. J Proteom $72: 367-378$

Uchida A, Jagendorf AT, Hibino T et al (2002) Effects of hydrogen peroxide and nitric oxide on both salt and heat stress tolerance in rice. Plant Sci 163:515-523

Valderrama R, Corpas FJ, Carreras A et al (2007) Nitrosative stress in plants. FEBS Lett $581: 453-461$

Van Breusegem F, Dat JF (2006) Reactive oxygen species in plant cell death. Plant Physiol 141:384-390

Vandelle E, Delledonne M (2011) Peroxynitrite formation and function in plants. Plant Sci 181:534-539

van Doorn WG (2005) Plant programmed cell death and the point of no return. Trends in Plant Sci 10:478-483

van Doorn WG, Woltering EJ (2005) Many ways to exit? Cell death categories in plants. Trends Plant Sci 10:117-122

van Doorn WG (2011) Classes of programmed cell death in plants, compared to those in animals. $\mathrm{J} \operatorname{Exp}$ Bot 62:4749-4761

Vianello A, Zancani M, Peresson C et al (2007) Plant mitochondrial pathway leading to programmed cell death. Physiol Plant 129:242-252

Vital SA, Fowler RW, Virgen A et al (2008) Opposing roles for superoxide and nitric oxide in the $\mathrm{NaCl}$ stress-induced upregulation of antioxidant enzyme activity in cotton callus tissue. 
Víteček J, Wünschová A, Petřek J et al (2007) Cell death induced by sodium nitroprusside and hydrogen peroxide in tobacco BY-2 cell suspension. Biol Plant 51:472-479

Wang H, Liang X, Wan Q, Wang X, Bi Y (2009) Ethylene and nitric oxide are involved in maintaining ion homeostasis in Arabidopsis callus under salt stress. Planta 230(2):293-307

Wang J, Li X, Liu Y, Zhao X (2010a) Salt stress induces programmed cell death in Thellungiella halophila suspension-cultured cells. J Plant Physiol 167:1145-1151

Wang Y, Chen C, Loake GJ, Chu C (2010b) Nitric oxide: promoter or suppressor of programmed cell death? Protein Cell 1:133-142

Wang H, Liang X, Huang $J$ et al (2010c) Involvement of ethylene and hydrogen peroxide in induction of alternative respiratory pathway in salt-treated Arabidopsis calluses. Plant Cell Physiol 51:1754-1765

Wang Y, Lin A, Loake GJ, Chu C (2013) $\mathrm{H}_{2} \mathrm{O}_{2}$-induced leaf cell death and the crosstalk of reactive nitric/oxygen species. J Integ Plant Biol 55:202-208

Wendehenne D, Durner J, Klessig DF (2004) Nitric oxide: a new player in plant signalling and defence responses. Curr Opin Plant Biol 7:449-455

Wimalasekera R, Tebartz F, Scherer GF (2011) Polyamines, polyamine oxidases and nitric oxide in development, abiotic and biotic stresses. Plant Sci 181:593-603

Woltering EJ (2010) Death proteases: alive and kicking. Trends Plant Sci 15:185-188

Wu XX, Ding HD, Chen JL et al (2010) Attenuation of salt-induced changes in photosynthesis by exogenous nitric oxide in tomato (Lycopersicon esculentum Mill. L.) seedlings. African J Biotech 9:7837-7846

Wu X, Zhu W, Zhang H et al (2011) Exogenous nitric oxide protects against salt-induced oxidative stress in the leaves from two genotypes of tomato (Lycopersicom esculentum Mill.). Acta Physiol Plant 33:1199-1209

Xie Y, Ling T, Han Y et al (2008) Carbon monoxide enhances salt tolerance by nitric oxidemediated maintenance of ion homeostasis and up-regulation of antioxidant defence in wheat seedling roots. Plant Cell Environ 31:1864-1881

Xı J, Yin H, Yang L et al (201 la) Differential salt tolerance in seedlings derived from dimorphic seeds of Atriplex centralasiatica: from physiology to molecular analysis. Planta 233:859-871

Xu S, Lou T, Zhao N et al (2011b) Presoaking with hemin improves salinity tolerance during wheat seed germination. Acta Physiol Plant 33:1173-1183

Yamaguchi K, Takahashi Y, Berberich T et al (2006) The polyamine spermine protects against high salt stress in Arabidopsis thaliana. FEBS Lett 580:6783-6788

Yamasaki H, Sakihama Y (2000) Simultaneous production of nitric oxide and peroxynitrite by plant nitrate reductase: in vitro evidence for the NR-dependent formation of active nitrogen species. FEBS Lett 468:89-92

Yamasaki H, Shimoji H, Ohshiro Y, Sakihama Y (2001) Inhibitory effects of nitric oxide on oxidative phosphorylation in plant mitochondria. Nitric Oxide 5:261-270

Yang Y, Xu S, An L, Chen N (2007) NADPH oxidase-dependent hydrogen peroxide production induced by salinity stress may be involved in the regulation of total calcium in roots of wheat. J Plant Physiol 164:1429-1435

Yang Y, Wei X, Shi R et al (2010) Salinity-induced physiological modification in the callus from halophyte Nitraria tangutorum Bobr. J Plant Growth Reg 29:465-476

Yoda H, Hiroi Y, Sano H (2006) Polyamine oxidase is one of the key elements for oxidative burst to induce programmed cell death in tobacco cultured cells. Plant Physiol 142:193-206

Yun BW, Feechan A, Yin M et al (2011) S-nitrosylation of NADPH oxidase regulates cell death in plant immunity. Nature 478:264-268

Zago E, Morsa S, Dat J et al (2006) Nitric oxide- and hydrogen peroxide-responsive gene regulation during cell death induction in tobacco. Plant Physiol 141:401-411

Zhang Y, Wang L, Liu Y et al (2006) Nitric oxide enhances salt tolerance in maize seedlings through increasing activities of proton-pump and $\mathrm{Na}^{+} / \mathrm{H}^{+}$antiport in the tonoplast. Planta 224:545-555

Zhang F, Wang Y, Yang $\mathrm{Y}$ et al (2007) Involvement of hydrogen peroxide and nitric oxide in salt 
Zhang B, Wang H, Wang P, Zhang $\mathrm{H}$ (2010) Involvement of nitric oxide synthase-dependent nitric oxide and exogenous nitric oxide in alleviating $\mathrm{NaCl}$ induced osmotic and oxidative stress in Arabidopsis thaliana. African J Agric Res 5:1713-1721

Zhao L, Zhang F, Guo J et al (2004) Nitric oxide functions as a signal in salt resistance in the calluses from two ecotypes of reed. Plant Physiol 134:849-857

Zhao MG, Tian QY, Zhang WH (2007a) Nitric oxide synthase-dependent nitric oxide production is associated with salt tolerance in Arabidopsis. Plant Physiol 144:206-217

Zhao M, Zhao X, Wu Y, Zhang L (2007b) Enhanced sensitivity to oxidative stress in an Arabidopsis nitric oxide synthase mutant. J Plant Physiol 164(6):737-745

Zheng C, Jiang D, Liu F et al (2009) Exogenous nitric oxide improves seed germination in wheat against mitochondrial oxidative damage induced by high salinity. Environ Exp Bot 67:222-227

Zeng CL, Liu L, Wang BR et al (201I) Physiological effects of exogenous nitric oxide on Brassica juncea seedlings under $\mathrm{NaCl}$ stress. Biol Plantarum 55:345-348

Zhu JK (2002) Salt and drought stress signal transduction in plants. Annu Rev Plant Biol $53: 247-273$

Zhu JK (2003) Regulation of ion homeostasis under salt stress. Curr Opin Plant Biol 6:441-445

Zottini M, Formentin E, Scattolin M et al (2002) Nitric oxide affects plant mitochondrial functionality in vivo. FEBS Lett 515:75-78 